\title{
The Win-Win-Win Papakonstantinidis Model: An Approach between Empathy and Conflict Strategy An Inquiry into the T. Schelling's -The Strategy of Conflictll (1960)
}

Prof. L. A. Papakonstantinidis

Professor Emeritus in Political Economy worked at the Local Government Dept (exPresident) of the School of Management and Economics (ex Director), Technological Educational Institute, University of PELOPONNESUS, Visby, Sweden

\begin{abstract}
The paper, based on the T. Schelling's (1960) strategy of conflict deals with the equilibrium conditions and strategy between empathy and conflict: we investigate if the winwin-win papakonstantinidis model ${ }^{1}$, as a conflict strategy could co-exists with the empathy as a pure behavioural condition focusing on improving the bargaining power Analytical, We investigate the interaction, empathy- global bargain, in a subjective and objective way 1 . Objectively as a conflict strategy that is an inherent element of every entity and 2 subjectively, through empathy and sensitivity We investigate the win-win-win papakonstantinidis from the empathy prism Especially, We investigate if empathy is included in conflict strategies Empathy definitions encompass a broad range of emotional states, including caring for other people and having a desire to help them; experiencing emotions that match another person's emotions; discerning what another person is thinking or feeling; and making less distinct the differences between the self and the other. It can also be understood as having the separateness of defining oneself and another blur Intuitive Bargaining and Bounded Reality in the Jackpot of Life ${ }^{2}$ The combined work of all 4 authors (Nash, Harsanyi, Selten, Gigerenzer) has definitely demonstrated the physical and psychological constraints in (cooperative/non-cooperative) bargaining and negotiation processes, with reference to economic gaming behavior, decisionmaking and legal interaction of players. As a result, we can safely assume that the =information gap' is the dominant key factor for humans to =make a living'. The sensitization process of the Papakonstantinidis model of the 3 win can achieve the full =angel's point', concerning a bottomup collective bargaining process by propelling meta-capitalist evolution forward, in terms of participatory capital formation. The intuitive 3 win approach calls for (capital- based) bargaining mutualism and has its analogy in the many living examples of biological mutualism.
\end{abstract}

Keywords: Strategy, Conflict, Empathy, Social bargain, The win-win-win papakonstantinidis model

\section{Definitions ${ }^{3}$}

\subsection{Empathy Definitions}

Empathy definitions encompass a broad range of emotional states, including caring for other people and having a desire to help them; experiencing emotions that match another person's emotions; discerning what another person is thinking or feeling; and making less distinct the

\footnotetext{
1 Papakonstantinidis LA (2002-08-14) "The win-win-win model" Euracademy Guide, presentation Visby University, Gotland Campus, SW

2 STEPHAN TURNIYK, 2020

${ }^{3}$ Merriam webster
} 
Prof. L. A. Papakonstantinidis

Professor Emeritus in Political Economy worked at the Local Government Dept (exPresident) of the School of Management and Economics (ex Director), Technological Educational Institute, University of PELOPONNESUS

differences between the self and the other. It can also be understood as having the separateness of defining oneself and another a blur

\section{Definition of empathy}

1: the action of understanding, being aware of, being sensitive to, and vicariously experiencing the feelings, thoughts, and experience of another of either the past or present without having the feelings, thoughts, and experience fully communicated in an objectively explicit manner also : the capacity for this

2: the imaginative projection of a subjective state into an object so that the object appears to be infused with it

Sympathy vs. Empathy

Sympathy and empathy are closely related words, bound by shared origins and the similar circumstances in which each is applicable, yet they are not synonymous. For one thing, sympathy is considerably older than empathy, having existed in our language for several hundred years before its cousin was introduced, and its greater age is reflected in a wider breadth of meaning. Sympathy may refer to "feelings of loyalty" or "unity or harmony in action or effect," meanings not shared by empathy. In the contexts where the two words do overlap, sympathy implies sharing (or having the capacity to share) the feelings of another, while empathy tends to be used to mean imagining, or having the capacity to imagine, feelings that one does not actually have.

It also is the ability to feel and share another person's emotions. Some believe that empathy involves the ability to match another's emotions, while others believe that empathy involves being tender hearted toward another person.

Having empathy can include having the understanding that there are many factors that go into decision making and cognitive thought processes. Past experiences have an influence on the decision making of today. Understanding this allows a person to have empathy for individuals who sometimes make illogical decisions to a problem that most individuals would respond with an obvious response. Broken homes, childhood trauma, lack of parenting and many other factors can influence the connections in the brain which a person uses to make decisions in the future.

Martin Hoffman is a psychologist who studied the development of empathy. According to Hoffman everyone is born with the capability of feeling empathy.

Since empathy involves understanding the emotional states of other people, the way it is characterized is derived from the way emotions themselves are characterized. If, for example, emotions are taken to be centrally characterized by bodily feelings, then grasping the bodily feelings of another will be central to empathy. On the other hand, if emotions are more centrally characterized by a combination of beliefs and desires, then grasping these beliefs and desires will be more essential to empathy. The ability to imagine oneself as another person is a sophisticated imaginative process. However, the basic capacity to recognize emotions is probably innate and may be achieved unconsciously. Yet it can be trained and achieved with various degrees of intensity or accuracy.

\subsection{Conflict Definitions}

Conflict definitions Among diverse theories of conflict - corresponding to the diverse meanings of the word -conflictll - a main dividing line is between those that treat conflict as a pathological state and seek its causes and treatment, and those that take conflict for granted and study the behaviour associated with it. Among the latter there is a further division between those that examine the participants in a conflict in all their complexity - with regard to both - rationalll and -irrationalll behaviour, conscious and unconscious, and to motivations as well as to calculations - and those that focus on the more rational, conscious, artful kind of behaviour. Crudely speaking, the latter treat conflict as a kind of contest, in which the participants are trying to 
Prof. L. A. Papakonstantinidis

Professor Emeritus in Political Economy worked at the Local Government Dept (exPresident) of the School of Management and Economics (ex Director), Technological Educational Institute, University of PELOPONNESUS

-win.ll A study of conscious, intellect-gent, sophisticated conflict behaviour - of successful behaviour - is like a search for rules of -correctll behaviour in a contest-winning sense.

We can call this field of study the strategy of conflict.

1. We can be interested in it for at least three reasons. We may be involved in a conflict ourselves; we all are, in fact, participants in international conflict, and we want to -winll in some proper sense. We may wish to understand how participants actually do conduct themselves in conflict situations; an understanding of -correctll play may give us a bench mark for the study of actual behaviour.

2.The term -strategyll is taken, here, from the theory of games which distinguishes games of skill, games of chance, and games of strategy, the latter being those in which the best course of action for each player depends on what the other players do. The term is intended to focus on the interdependence of the adversaries' decisions and on their expectations about each other's behaviour.

3.We may wish to control or influence the behaviour of others in conflict, and we want, therefore, to know how the variables that are subject to our control can affect their behaviour.

4.If we confine our study to the theory of strategy, we seriously restrict ourselves by the assumption of rational behaviour - not just of intelligent behaviour, but of behaviour motivated by a con-scions calculation of advantages, a calculation that in turn is leased on an explicit and internally consistent value system. We thus limit the applicability of any results we reach. If our interest is the study of actual behaviour, the results we reach under this constraint may prove to be either a good approximation of reality or a caricature. Any abstraction runs a risk of this sort, and we have to be prepared to use judgment with any results we reach.

\section{Introduction}

Let's start from the conflict situation, as the situations where there is a common interest as well as conflict between adversaries: negotiations, war and threats of war, criminal deterrence, extortion, tacit bargaining. It proposes enlightening similarities between, for instance, maneuvering in limited war and in a traffic jam; deterring the Russians and one's own children; the modern strategy of terror and the ancient institution of hostages (Thomas Schelling) Based on Schelling's (1960) ${ }^{4}$ ideas we choose the prisoner' and the hawk and dove games because they are simplest negotiation environment with inequity distribution in equilibrium ${ }^{5}$ to determine the relationship of 3-win with empathy in every human behaviour This plot (if any) seems to be the generating cause of any behaviour in any bazaar between two - and much more in three negotiators - The contribution of the third is of crucial importance, while the negotiation between 4 and above weakens the negotiation because it allows for collusion (Theocharis, 1955), something that the three-person negotiation does not allow

- to facilitate to clarify the relation (if any) between -tacit knowledgell and empathy and sympathy in any bargain

- To create a coherent base of arguments toward proving the influence of the empathy over a preferences' scale

- Also to find relations between social preferences- bargaining behaviour

\footnotetext{
${ }^{4}$ Thomas Schelling (1960) "The Strategy of Conflict" -Harvard University Press, updating 1980

${ }^{5}$ The name "hawk-dove" refers to a situation in which there is a competition for a shared resource and the contestants can choose either conciliation or conflict; this terminology is most commonly used in biology and evolutionary game theory. From a game-theoretic point of view, "chicken" and "hawk-dove" are identical; the different names stem from parallel development of the basic principles in different research areas.
} 


\section{Prof. L. A. Papakonstantinidis}

Professor Emeritus in Political Economy worked at the Local Government Dept (exPresident) of the School of Management and Economics (ex Director), Technological Educational Institute, University of PELOPONNESUS

\subsection{Conflict Strategy}

The term - strategyll is taken, here, from the theory of games which distinguishes games of skill, games of chance, and games of strategy, the latter being those in which the best course of action for each player depends on what the other players do. The term is intended to focus on the interdependence of the adversaries' decisions and on their expectations about each other's behaviour.

We may wish to control or influence the behaviour of others in conflict, and we want, therefore, to know how the variables that are subject to our control can affect their behaviour.

If our interest is the study of actual behaviour, the results we reach under this constraint may prove to be either a good approximation of reality or a caricature. Any abstraction runs a risk of this sort, and we have to be prepared to use judgment with any results we reach.

The advantage of cultivating the area of -strategyll for theoretical development is not that, of all possible approaches, it is the one that evidently stays closest to the truth, but that the assumption of rational behaviour is a productive one. It gives a grip on the subject that is peculiarly conducive to the development of theory. It permits us to identify our own analytical processes with those of the hypothetical participants in a conflict; and by demanding certain kinds of consistency in the behaviour of our hypothetical participants; we can examine alternative courses of behaviour according to whether or not they meet those standards of consistency. The premise of -rational behaviourll is a potent one for the production of theory. Whether the resulting theory provides good or poor insight into actual behaviour is, I repeat, a matter for subsequent judgment.

But, in taking conflict for granted, and working with an image of participants who try to - win, ll a theory of strategy does not deny that there are common as well as conflicting interests among the participants. In fact, the richness of the subject arises from the fact that, in international affairs, there is mutual dependence as well as opposition. Pure conflict, in which the interests of two antagonists are completely opposed, is a special case; it would arise in a war of complete extermination, otherwise not even in war. For this reason, -winningll in a conflict does not have a strictly competitive meaning; it is not winning relative to one's adversary. It means gaining relative to one's own value system;

According to Luis Alejandro Palacio Garcia* Alexandra Cortes Aguilar (2010) a player can increase his bargaining power in a negotiation process if he decide to bind himself in a credible way, rejecting with premeditation some opportunities. The lack of freedom of a player has strategic value because it changes the expectations that others have on the future answers that he could give, and this restriction can be used in his own benefit. It is easy to identify examples of commitment in daily life or economic situations, but military strategy is the most salient case because conflict is inherent to it. Announcing that our army is ready to fight up to the last breath is essential to deter an opponent from entering into a bloody battle, since what is looked for is that the rival gives himself up without wasting valuable resources.

In Schelling's (1960) seminal work, he distinguishes between two different types of commitment: ordinary commitment and threats. The ordinary commitment is the possibility of playing first, announcing that our decision has already been taken and that it is impossible to be changed, which forces the opponent to take the final decision. This is the case of the famous military strategy -burn the shipsll illustrated above. On the other hand, threats occur when the second mover convincingly pledges to respond, in a specified contingent way, to the opponent's earlier choice (Hirshleifer, 2000).

\footnotetext{
${ }^{6}$ It has been taken from Thomas Schelling (1981 edition ) "The strategy of conflict", ed Harvard University, Press
} 
Prof. L. A. Papakonstantinidis

Professor Emeritus in Political Economy worked at the Local Government Dept (exPresident) of the School of Management and Economics (ex Director), Technological Educational Institute, University of PELOPONNESUS

The distinctive feature of a threat is that the sender has no incentive to carry it out either before the event or after. This leads us to questioning the credibility of this strategic movement, because announcing that a player is going to play in an opposite way to the game incentives does not change the opponent's beliefs. The message - never retreat, never surrenderll is not enough to increase the bargaining power; it is necessary that the specified action is actually the one that will be played. A message is credible if it makes clear to the opponent that the play cannot change, because it is too costly or even impossible to turn back.

\section{Analysis \\ Chapter 1 \\ International Strategy \\ 1. The Strategy of Conflict}

STRATEGY is not concerned with the efficient application of force but with the exploitation of potential force. It is concerned not just with enemies who dislike each other but with partners who distrust or disagree with each other. It is concerned not just with the division of gains and losses between two claimants but with the possibility that particular outcomes are worse (better) for both claimants than certain other outcomes. In the terminology of game theory, most interesting international conflicts are not - constant-sum gamesll but - variable-sum gamesll: the sum of the gains of the participants involved is not fixed so that more for one inexorably means less for the other. There is a common interest in reaching outcomes that are mutually advantageous.

To study the strategy of conflict ${ }^{7}$ is to take the view that most conflict situations are essentially bargaining situations. They are situations in which the ability of one participant to gain his ends is dependent to an important degree on the choices or decisions that the other participant will make. The bargaining may be explicit, as when one offers a concession; or it may be by tacit maneuver, as when one occupies or evacuates strategic territory. It may, as in the ordinary haggling of the market-place, take the status quo as its zero point and seek arrangements that yield positive gains to both sides; or it may involve threats of damage, including mutual damage, as in a strike, boycott, or price war, or in extortion.

Viewing conflict behavior as a bargaining process is useful in keeping us from becoming exclusively preoccupied either with the conflict or with the common interest. To characterize the maneuvers and actions of limited war as a bargaining process is to emphasize that, in addition to the divergence of interest over the variables in dispute, there is a powerful common interest in reaching an outcome that is not enormously destructive of values to both sides. A -successfulll employees' strike is not one that destroys the employer financially, it may even be one that never takes place. Something similar can be true of war.

\section{Deterrence}

Deterrence is concerned with influencing the choices that another party will make, and doing it by influencing his expectations of how we will behave. It involves confronting him with evidence for believing that our behavior will be determined by his behavior. But what configuration of value systems for the two participants - of the - payoffs, $\|$ in the language of game theory - makes a deterrent threat credible? How do we measure the mixture of conflict and common interest required to generate a -deterrencell situation? What communication is required, and what means of authenticating the evidence communicated? What kind of - rationalityll is required of the party

\footnotetext{
7 Thomas Schelling (1981 edition )"The strategy of conflict", ed Harvard University, Press
} 


\section{Prof. L. A. Papakonstantinidis}

Professor Emeritus in Political Economy worked at the Local Government Dept (exPresident) of the School of Management and Economics (ex Director), Technological Educational Institute, University of PELOPONNESUS

to be deterred - a knowledge of his own value system, an ability to perceive alternatives $=$ Progress is being made.

Daniel Ellsberg included a lecture on -The Theory and Practice of Blackmail, II and one on -The Political Uses of Madness, $\|$ in his series on -The Art of Coercion, $\|$ sponsored by the Lowell Institute, Boston, and March 1959 And to calculate with probabilities, an ability to demonstrate (or an inability to conceal) his own rationality What is the need for trust, or enforcement of promises? Specifically, in addition to threatening damage, need one also guarantee to withhold the damage if compliance is forthcoming; or does this depend on the configuration of - payoffs $\|$ involved? What -legal system, II communication system, or information structure is needed to make the necessary promises enforceable?

The idea of -deterrencell has had an evolution that is instructive for our purpose. It is a dozen years since deterrence was articulated as the keystone of our national strategy, and during those years the concept has been refined and improved. We have learned that a threat has to be credible to be efficacious, and that its credibility may depend on the costs and risks associated with fulfillment for the party making the threat. We have developed the idea of making a threat credible by getting ourselves com- mitted to its fulfillment, through the stretching of a -trip wirell across the enemy's path of advance, or by making fulfillment a matter of national honor and prestige - as in the case, say, of the Formosa Resolution. We have recognized that a readiness to fight limited war in particular areas may detract from the threat of massive retaliation, by preserving the choice of a lesser evil if the contingency arises. We have considered the possibility that a retaliatory threat may be more credible if the means of carrying it out and the responsibility for retaliation are placed in the hands of those whose resolution is strongest, as in recent suggestions for - nuclear sharing.\|l We have observed that the rationality of the adversary is pertinent to the efficacy of a threat, and that madmen, like small children, can often not be controlled by threats. We have recognized that the efficacy of the threat may depend on what alternatives are available to the potential enemy, who, if he is not to react like a trapped lion, must be left some tolerable recourse. We have come to realize that a threat of all-out retaliation gives the enemy every incentive, in the event he should choose not to heed the threat, to initiate his transgression with an all-out strike at us; it eliminates lesser courses of action and forces him to choose between extremes. We have learned that the threat of massive destruction may deter an enemy only if there is a corresponding implicit promise of non destruction in the event he complies, so that we must consider whether too great a capacity to strike him by surprise may induce him to strike first to avoid being disarmed by a first strike from us. And recently, in connection with the so-called -measures to safeguard against surprise attack, ll we have begun to consider the possibility of improving mutual deterrence through arms control.

What is impressive is not how complicated the idea of deterrence has become, and how carefully it has been refined and developed, but how slow the process has been, how vague the concepts still are, and how inelegant the current theory of deterrence is. This is not said to depreciate the efforts of people who have struggled with the deterrence concept over the last dozen years. On strategic matters of which deterrence is an example, those who have tried to devise policies to meet urgent problems have had little or no help from an already existing body of theory, but have had to create their own as they went along. There is no scientific literature on deterrence that begins to compare with, say, the literature on inflation, Asiatic flu, elementary-school reading, or smog.

Furthermore, those who have grappled with ideas like deterrence, being motivated largely by immediate problems, have not primarily been concerned with the cumulative process of developing a theoretical structure.

Training negotiation is difficult because it is a complex, dynamic activity that involves multiple parties. It is often not clear how to create situations in which students can practice negotiation 


\section{Prof. L. A. Papakonstantinidis}

Professor Emeritus in Political Economy worked at the Local Government Dept (exPresident) of the School of Management and Economics (ex Director), Technological Educational Institute, University of PELOPONNESUS

or how to measure students' progress. Some have begun to address these issues by creating artificial software agents with which students can train. These agents have the advantage that they can be-reset,ll and played against multiple times. This allows students to learn from their mistakes and try different strategies. However, these agents are often based on normative theories of how negotiators should conduct themselves, not necessarily how people actually behave in negotiations. Here, we take a step toward addressing this gap by developing an agent grounded in a cognitive architecture, ACT-R. This agent contains a model of theory-ofmind, the ability of humans to reason about the mental states of others. It uses this model to try to infer the strategy of the opponent and respond accordingly. In a series of experiments, we show that this agent replicates some aspects of human performance, is plausible to human negotiators, and can lead to learning gains in a small-scale negotiation task.

Negotiation is an important tool through which people work with others to better satisfy their needs. Negotiation is ubiquitous, and its contexts range from mundane daily occurrences (e.g., deciding how to split the check for dinner) to historic, far-reaching events (e.g., international conflict resolutions). For this reason, it is important for people to know how to effectively approach negotiations in order to achieve fair, mutually beneficial agreements. However, training negotiation is challenging because it is a complex activity that involves at least two parties. So people must practice either in groups or with simulated partners. Cognitive agents are a promising tool for developing such agents because they can simulate human memory, biases, and problem solving strategies, allowing students to get a better sense of how real negotiators will respond to various circumstances. Here we develop and validate a cognitive agent that can perform a singleissue bargaining task.

\section{Threats}

Every negotiator faces threats at the bargaining table. How should you respond when the other side threatens to walk away, file a lawsuit, or damage your reputation? These negotiation tips will help.

Direct counterattacks are rarely the answer. Your threats may not be as powerful or credible as the other side's, or they could launch an uncontrollable spiral of conflict. Alternatively, you might be tempted to immediately concede to your opponent's demands, but that would only reinforce his domineering tactics.

Our DEAL approach allows you to respond to threats without conveying weakness or escalating the conflict, redirecting talks toward a focus on each other's interests.

\section{Diagnose the Threat}

Sometimes threats emerge as overt declarations: -If you can't follow through on the contract terms, I'll let the community know what kind of show you're running.ll

Other times they're more subtle: -You know, I'd hate for this to hurt your reputation. II

Regardless, it's critical that you seek to understand what provoked the threat, as its cause could determine your response in negotiation.

The first step in effective threat diagnosis is to remove yourself from the situation - physically and/or psychologically. You might suggest to your counterpart that it's time for a break, or imagine that you're an outside observer trying to evaluate the threat more objectively. By detaching yourself from the situation, you can calm your emotions and truly hear what the other side is saying.

Next, consider the motivation behind the threat, which may identify the threat issuer as one of these types:

The victim: If your counterpart was feeling frustrated or offended, the threat may have emerged from his basic need to be heard and acknowledged.

The pragmatist: This straight shooter is simply informing you of the real constraints she faces or the strong outside alternatives she has. 
Prof. L. A. Papakonstantinidis

Professor Emeritus in Political Economy worked at the Local Government Dept (exPresident) of the School of Management and Economics (ex Director), Technological Educational Institute, University of PELOPONNESUS

The bluffer: He may be brandishing his power due to insecurity or a desire to dominate. If so, the threat may be more ruse than reality.

\section{Express Understanding}

As customer service representatives have been taught, the best way to handle a -victimll is to listen to his grievances, acknowledge his feelings, and apologize for his troubles. Such moves can be palliative. New York University professor Tom Tyler has shown that when individuals in conflict express their emotions and tell their side of the story, they're more satisfied with outcomes- even when these outcomes aren't in their favor. Expressing understanding can defuse tensions and reduce the risk of additional threats, but be careful not to reward tirades with concessions ${ }^{8}$.

Threats and responses to threats, reprisals and counter-re-presales, limited war, arms races, brinkmanship, surprise attack, trusting and cheating can be viewed as either hot-headed or coolheaded activities. In suggesting that they can usefully be viewed, in the development of theory, as cool-headed activities, it is not asserted that they are in fact entirely cool-headed. Rather it is asserted that the assumption of rational behavior is a productive one in the generation of systematic theory. If behavior were ac-tally cool-headed, valid and relevant theory would probably be easier to create than it actually is. If we view our results as a bench mark for further approximation to reality, not as a fully adequate theory, we should manage to protect ourselves from the worst results of a biased theory. Furthermore, theory that is based on the assumption that the participants coolly and - rationallyll calculate their advantages according to a consistent value system forces us to think more thoroughly about the meaning of -irrationality. II Decisionmakers are not simply distributed along a one-dimensional scale that stretches from complete rationality at one end to complete ire-rationality at the other. Rationality is a collection of attributes, and departures from complete rationality may be in many dif-ferment directions. Irrationality can imply a disorderly and inconsistent value system, faulty calculation, an inability to receive messages or to communicate efficiently; it can imply random or haphazard influences in the reaching of decisions or the trans-mission of them, or in the receipt or conveyance of information; and it sometimes merely reflects the collective nature of a decision among individuals who do not have identical value systems and whose organizational arrangements and communication sys- teams do not cause them to act like a single entity.

As a matter of fact, many of the critical elements that go into a model of rational behavior can be identified with particular types of rationality or irrationality. The value system, the commedication system, the information system, the collective decision process, or a parameter representing the probability of error or loss of control, can be viewed as an effort to formalize the study of -irrationality.ll Hitler, the French Parliament, the commander of a bomber, the radar operators at Pearl Harbor, Khrushchev, and the American electorate may all suffer from sine kinds of -irrationality, ll but by no means the same kinds. Some of them can be accounted for within a theory of rational behavior. (Even the neurotic, with inconsistent values and no method of reconciling them, motivated to suppress rather than to reconcile his conflicting goals, may for some purposes be viewed as a pair of -rationalll entities with distinct value systems, reaching collective decisions through a voting process rational behavior can be identified with particular types of rationality or irrationality. The value system, the com-medication system, the information system, the collective decision process, or a parameter representing the probability of error or loss of control, can be viewed as an effort to formalize the study of -irrationality. II Hitler, the French Parliament, the commander of a bomber, the radar operators at Pearl Harbor, Khrushchev, and the American electorate may all suffer from sine kinds of -irrationality, ll but by no means the same kinds. Some of them can be accounted for within a theory of rational behavior. (Even the neurotic, with inconsistent values and no method of reconciling them, motivated to suppress rather than to reconcile his conflicting goals, may for some purposes be viewed as a pair of

\footnotetext{
${ }^{8}$ PON STAFF - ON JULY 16TH, 2020 / How to Deal with Threats: 4 Negotiation Tips for Managing Conflict at the Bargaining Table Conflict resolution negotiation tips for using the DEAL method-CONFLICT RESOLUTION
} 
Prof. L. A. Papakonstantinidis

Professor Emeritus in Political Economy worked at the Local Government Dept (exPresident) of the School of Management and Economics (ex Director), Technological Educational Institute, University of PELOPONNESUS

-rationalll entities with distinct value systems, reaching collective decisions through a voting process $^{9}$

\section{The 3rd participant}

The suggested -win-win-win papakonstantinidis modelll introduces the third participant We read in Thomas Schelling - The stradegy of conflictll:

-....How is the situation affected by a third participant, who has his own mixture of conflict and common interest with those already present, who has access to or control of the communication system, whose behavior is rational or irrational in one sense or another, who enjoys trust or some means of contract enforcement with one or another of the two principals? How are these questions affected by the existence of a legal system that permits and prohibits certain actions, that is available to inflict penalty on non fulfillment of contract, or that can demand authentic information from the participants. To what extent can we ration-alike concepts like -reputation, -face,ll or-trust,ll in terms of a real or hypothetical legal system, in terms of modification of the participants' value systems, or in terms of relationships of the players concerned to additional participants, real or hypotheticcal? This brief sample of questions may suggest that there is scope for the creation of -theory. II There is something here that looks like a mixture of game theory, organization theory, communication theory, theory of evidence, theory of choice, and theory of collective decision. It is faithful to our definition of -strategyll: it takes conflict for granted, but also assumes common interest between the adversaries; it assumes a -rationalll valuemaximizing-in mode of behavior; and it focuses on the fact that each participant's -bestll choice of action depends on what he expects the other to do, and that -strategic behaviorll is concerned with influencing another's choice by working on his expectation of how one's own behavior is related to his. There are two points worth stressing. One is that, though -strategy of conflictll sounds cold-blooded, the theory is not con-corned with the efficient application of violence or anything of the sort; it is not essentially a theory of aggression or of resistance or of war. Threats of war, yes, or threats of anything else; but it is the employment of threats, or of threats and promises, or more generally of the conditioning of one's own behavior on the be-savior of others, that the theory is about...ll Second, such a theory is nondiscriminatory as between the conflict and the common interest, as between its applicability to potential enemies and its applicability to potential friends. The theory degenerates at one extreme if there is no scope for mutual accommodation, no common interest at all even in avoiding mu-teal disaster; it degenerates at the other extreme if there is no conflict at all and no problem in identifying and reaching commoon goals. But in the area between those two extremes the theory is noncommittal about the mixture of conflict and common interest ; we can equally well call it the theory of precarious partnership or the theory of ${ }^{10}$ incomplete antagonism.

\section{Bargaining Power -the Power to Bind Oneself}

Bargaining power, $\|$-bargaining strength, $\|$-bargaining skillll suggest that the advantage goes to the powerful, the strong, or the skillful. It does, of course, if those qualities are defined to mean only that negotiations are won by those who win. But, if the terms imply that it is an advantage to be more intelligent or more skilled in debate, or to have more financial resources, more physical strength, more military potency, or more ability to withstand losses, then the term does a disservice. These qualities are by no means universal advantages in bargaining situations; they often have a contrary value.

The sophisticated negotiator may find it difficult to seem as obstinate as a truly obstinate man. If a man knocks at a door and says that he will stab himself on the porch unless given $\$ 10$, he is more likely to get the $\$ 10$ if his eyes are bloodshot. The threat of mutual destruction cannot be

\footnotetext{
9 Thomas Schelling (1981 edition )“The strategy of conflict”, ed Harvard University, Press

${ }^{10}$ Win-win-win papakonstantinidis model, 2002 papakonstantinidis Visby university, Gotlant Campus, SW
} 
Prof. L. A. Papakonstantinidis

Professor Emeritus in Political Economy worked at the Local Government Dept (exPresident) of the School of Management and Economics (ex Director), Technological Educational Institute, University of PELOPONNESUS

used to deter an adversary who is too unintelligent to comprehend it or too weak to enforce his will on those he represents. The government that cannot control its balance of payments, or collect taxes, or muster the political unity to defend itself, may enjoy assistance that would be denied it if it could control its own resources. And, to cite an example familiar from economic theory, - price leadershipll in oligopoly may be an unprofitable distinction evaded by the small firms and assumed perforce by the large one.

Bargaining power has also been described as the power to fool and bluff,-the ability to set the best price for yourself and fool the other man into thinking this was your maximum offer.ll 1 Fooling and bluffing are certainly involved; but there are two kinds of fooling. One is deceiving about the facts; a buyer may lie about his income or misrepresent the size of his family. The other is purely tactical. Suppose each knows everything about the other, and each knows what the other knows. What is there to fool about? The buyer may say that, though he'd really pay up to twenty and the seller knows it, he is firmly resolved as a tactical matter not to budge above sixteen. If the seller capitulates, was he fooled? Or was he convinced of the truth? Or did the buyer really not know what he would do next if the tactic failed? If the buyer really -feelsll himself firmly resolved, and bases his resolve on the conviction that the seller will capitulate, and the seller does, the buyer may say afterwards that he was - not fooling.ll Whatever has occurred, it is not adequately conveyed by the notions of bluffing and fooling.

How does one person make another believe something? The answer depends importantly on the factual question, -Is it true?\|I It is easier to prove the truth of something that is true than of something false. To prove the truth about our health we can call on a reputable doctor; to prove the truth about our costs or income we may let the person look at books that have been audited by a reputable firm or the Bureau of Internal Revenue. But to Persuade him of something false we may have no such convincing evidence.

\section{Intersecting Negotiations}

If a union is simultaneously engaged, or will shortly be engaged, in many negotiations while the management has no other plants and deals with no other unions, the management cannot convincingly stake its bargaining reputation while the union can. The advantage goes to the party that can persuasively point to an array of other negotiations in which its own position would be prejudiced if it made a concession in this one. (The - reputation valuell of the bargain may be less related to the outcome than to the firmness with which some initial bargaining position is adhered to.) Defense against this tactic may involve, among other things, both misinterpretation of the other party's position and an effort to make the eventual outcome in- commensurable with the initial positions. If the subjects under negotiation can be enlarged in the process of negotiation, or the wage figure replaced by fringe benefits that cannot be reduced to a wage equivalent, an -outll is provided to the party that has committed itself; and the availability of this - outll weakens the commitment itself, to the disadvantage of the committed party.

\section{The Possibility on Compensation}

Agreement may be dependent on some means of redistributing costs or gains. If duopolists, for example, divide markets in a way that maximizes their combined profits, some initial accrual of profits is thereby determined; any other division of the profits requires that one firm be able to compensate the other. If the fact of compensation would be evidence of illegal collusion, or if the motive for compensation would be misunderstood by the stock-holders, or if the two do not sufficiently trust each other, some less optimum level of joint profits may be required in order that the initial accrual of profits to the two firms is in closer accordance with an agreed division of gains between them.

\section{Evoluntary Game}




\section{Prof. L. A. Papakonstantinidis}

Professor Emeritus in Political Economy worked at the Local Government Dept (exPresident) of the School of Management and Economics (ex Director), Technological Educational Institute, University of PELOPONNESUS

Parallel or at the same time that non-cooperative game theory has become a standard tool in economics, it has also come under increasingly critical scrutiny from theorists and experimentalists. Non-cooperative game theory, like neoclassical economics, is built on two heroic assumptions:

Maximization-every economic agent is a rational decision maker with a clear understanding of the world; and consistency-the agent's understanding, in particular, expectations, of other agents' behavior, is correct (i.e., the overall pattern of individual optimizing behavior forms a Nash equilibrium). These assumptions are no less controversial in the context of non-cooperative game theory than they are in neoclassical economics. A major challenge facing non-cooperative game theorists today is that of providing a compelling justification for these two assumptions. As I will argue here, many of the traditional justifications are not compelling. But without such justification, the use of game theory in applications is problematic. The appropriate use of game theory requires understanding when its assumptions make sense and when they do not.

In some ways, the challenge of providing a compelling justification is not a new one. A major complaint other social scientists (and some economists) have about economic methodology is the central role of the maximization hypothesis. A common informal argument is that any agent not optimizing - in particular, any firm not maximizing profits-will be driven out by market forces. This is an evolutionary argument, and as is well known, Charles Darwin was led to the idea of natural selection from reading Thomas Malthus.

Much of the work in evolutionary game theory is motivated by two basic questions:

1. Do agents play Nash equilibrium?

2. Given that agents play Nash equilibrium, which equilibrium do they play?

Evolutionary game theory formalizes and generalizes the evolutionary argument given above by assuming that more successful behavior tends to be more prevalent. The canonical model has a population of players interacting over time, with their behavior adjusting over time in response to the payoffs (utilities, profits) that various choices have historically received. These players could be workers, consumers, firms, etc. The focus of study is the dynamic behavior of the system. The crucial assumptions are that there is a population

3 Or perhaps economists have chosen to study

only those properties that are shared by all equilibria. For example, different competitive equilibria have different income distributions.

of players, these players are interacting, and the behavior is naive (in two senses: players do not believe-understand- that their own behavior potentially affects future play of their opponents, and players typically do not take into account the possibility that their opponents are similarly engaged in adjusting their own behavior). It is important to note that successful behaviour becomes more prevalent not just because market forces select against unsuccessful behavior, but also because agents imitate successful behavior ${ }^{11}$.

Since evolutionary game theory studies populations playing games, it is also useful for studying social norms and conventions. Indeed, many of the motivating ideas are the same. The evolution of conventions and social norms is an instance of players learning to play an equilibrium. A convention can be thought of as a symmetric equilibrium of a coordination game. Examples include a population of consumers who must decide which type of good to pur-chase (in a world of competing standards); a population of workers who must decide how much effort to exert; a population of traders at a fair (market) who must decide how aggressively to bargain; and a population of drivers randomly meeting at intersections who must decide who gives way to whom. Evolutionary game theory has provided a qualified affirmative answer to the first question: In a range of settings, agents do (eventually) play Nash. There is thus support for equilibrium analysis

${ }^{11}$ GEORGE J. MAILATH "Do People Play Nash Equilibrium? Lessons From Evolutionary Game Theory" Journal of Economic Literature 
Prof. L. A. Papakonstantinidis

Professor Emeritus in Political Economy worked at the Local Government Dept (exPresident) of the School of Management and Economics (ex Director), Technological Educational Institute, University of PELOPONNESUS

in environments where evolutionary arguments make sense. Equilibrium is best viewed as the steady state of a community whose members are myopically groping toward maximizing behavior. This is in marked contrast to the earlier view (which, as I said, lacks satisfactory foundation), according to which game theory and equilibrium analysis are the study of the interaction of (ultra-) rational agents with a large amount of (common) knowledge.

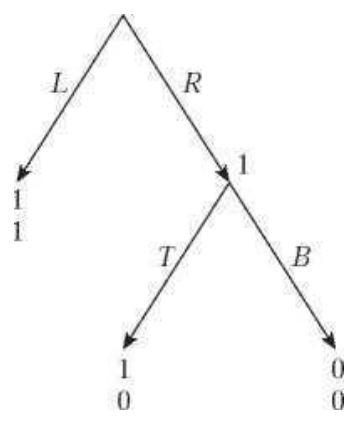

\section{Chapter 2}

\section{Mentalizing and Empathizing}

Standard models of choice in economics and game theory descend from the famous homo economicus paradigm: they assume that decision makers are fully rational and self-interested, always making an optimal use of information to obtain the maximum payoff available (Kreps 1990; Osborne and Rubinstein 1994; Camerer 2003). Game theory is the mathematical language describing rational choice in situations of strategic interaction, i.e., in multi-agent choice problems (henceforth: =games') in which the outcome of an agent's decision depends on the decisions of all other agents involved: in this case, the rationality paradigm implies that any acceptable strategy profile and solution concept (Nash equilibrium, backward and forward induction, signaling, etc.) must incorporate the decision maker's correct understanding of other decision makers' states of mind, i.e., of their beliefs and motivations as these can be inferred from the game incentive structure ${ }^{12}$.

The large body of laboratory evidence collected by behavioral and experimental economists in the last two decades has convincingly shown that human agency is at odds with the homo economicus paradigm in multiple ways: more specifically, laboratory data show that individuals are often unable to analyze an interactive decision problem from the perspective of the other decision maker(s). At the same time, however, they do seem to take others' preferences into account, as many of their choices can only be explained by referring to motivations like altruism, cooperation, fairness and desire to reciprocate (for extensive reviews, see Kagel and Roth 1995; Camerer 2003; Chaudhuri 2009).

The descriptive inadequacy of the _perfect rationality plus self-interest' yardstick is by now fairly established within economics, although no alternative framework has so far gained consensus, not even among those economists more inclined to abandon standard models based on utility maximization in favor of greater realism. The recent encounter with neuroscience has provided some of them with the unprecedented opportunity to open the -black boxll of brain functioning and to directly tackle the core of our comprehension of human interactive decisions: the question of when and why we are able to understand and share' other people's states of mind and feelings.

\footnotetext{
${ }^{12}$ Devetag Giovanna Di Guida Sibilla Natalia Montinari (2012) "Theory of Mind in the Social Sciences: An Experiment On Strategic Thinking in Children"
} 
Prof. L. A. Papakonstantinidis

Professor Emeritus in Political Economy worked at the Local Government Dept (exPresident) of the School of Management and Economics (ex Director), Technological Educational Institute, University of PELOPONNESUS

One of the most influential areas of research, originated within cognitive science and rapidly spread across disciplines as diverse as anthropology, economics and philosophy, is -mind readingll or perspective-taking, i.e., the ability - shared by humans and by a limited number of nonhuman primates - to understand, interpret and reason about the mental states of others (Cacioppo, Visser, and Pickett 2006). Social neuroscience investigates the neural circuits involved in our capacity to understand other peoples' intentions, beliefs, and moods, a complex set of abilities globally referred to as-theory of mindll or -mentalizingll (Saxe 2006; Stone and Gerrans 2006). Alongside with the study of how people think about other people and represent their mental states, scholarly attention has been dedicated to understand what enables people to share the feelings of others, referred to as -empathyll. Normal adults are capable of both mentalizing and empathizing to a good extent, while children acquire these abilities gradually (Eisenberg and Mussen 1989; Murnighan and Saxon 1998; Warneken and Tomasello 2007) and autistic children and adults do not seem to possess a theory of mind, which might explain their failures in communication and several other_social cognition' skills (e.g., Baron-Cohen 1995) Perspective-taking, in its double version of mentalizing and empathizing, is the means by which human beings and other primates influence and are influenced by each other, contributing to the emergence of norms of cooperation within societies. For these reasons, they are both extremely interesting topics of investigation for social scientists and neuroscientists alike.

In game theory perspective-taking is essential: as a consequence, understanding when and why we are capable of -seeingll a game from the point of view of other decision makers allows us to better understand our mental models of strategic interaction, which may not at all coincide with the_truell incentive structure (Camerer 1998): in other words, as recent evidence also suggests, in many settings we may be playing the _wrong' game (Devetag and Warglien 2008).

\section{Knowledge Creation and Transfer- Types of Behavior}

Knowledge is one of the basic production factors owned by enterprises, and knowledge management is one of the main dynamic capabilities on which enterprises can base their competitive advantages. The creation, transfer, and later use of knowledge have become increasingly important, and multinational corporations (MNCs), being scattered in various places, constitute the appropriate environment to implement knowledge management processes meant to maximize their intellectual assets. This chapter has as its aim to answer three questions: (a) what actions do MNCs undertake in order to set knowledge management processes in motion; (b) what main variables impact on their knowledge creation capability; and (c) what main variables impact on their knowledge transfer capability? A qualitative research work based on a multiple case study has served to achieve that aim, allowing us to carry out an exploratory study of six MNCs which have shown their proactivity in the knowledge management area. The results of the analysis have led to eight propositions which highlight the most relevant variables facilitating the processes for the creation and transfer of knowledge within a $\mathrm{MNC}^{13}$.

\begin{tabular}{|l|l|l|l|}
\hline $\begin{array}{l}\text { Type of } \\
\text { lowledge-1 }\end{array}$ & $\begin{array}{l}\text { Type of } \\
\text { lowledge-2 }\end{array}$ & Synthesis & Resulted Behavior \\
\hline tacit & tacit & $\begin{array}{l}\text { Sympathetic/ } \\
\text { Intuition }\end{array}$ & Socialization \\
\hline tacit & codified & Conceptual & Externalization \\
\hline
\end{tabular}

${ }^{13}$ A Qualit Patrocinio Zaragoza-Saez (University of Alicante, Spain), Enrique Claver-Cortes (University of Alicante, Spain) and Diego Quer-Ramon (University of Alicante, Spain)(2009) ative Study of Knowledge Management: The Multinational Firm Point of View- : Handbook of Research on Knowledge-Intensive Organizations 
Prof. L. A. Papakonstantinidis

Professor Emeritus in Political Economy worked at the Local Government Dept (exPresident) of the School of Management and Economics (ex Director), Technological Educational Institute, University of PELOPONNESUS

\begin{tabular}{|l|l|l|l|}
\hline codified & tacit & Procedural & Internalization \\
\hline codified & codified & Systemic & Networking \\
\hline sympathetic & systemic & Conceptual & Sensitization \\
\hline systemic & systemic & Procedural & Strategic \\
\hline
\end{tabular}

Papakonstantinidis, 2003

This table shows us, all the possible combinations of different types of knowledge and its results of a -new behaviorll coming from this combination: For example, -tacitll to -tacitll knowledge leads to -sympatheticll thus producing - socializationll as a form of new behavior etc. Sensitization is introduced (regarding to integrated information), as the main variable of the bargain (the third part of the negotiationll/ the -Cll factor) The implementation of the LEADER EU (EEC) Commission Initiative of the in less developed mountainous and island regions of my country was an excellent opportunity implementing the - win-win-win papakonstantinidis modelll in the form of sensitization of the local population around a central priority theme

\section{Knowledge transfer ${ }^{14}$}

Knowledge transfer systems aid you in streamlining your knowledge which ensures that everyone on your team has the information they need to keep your business running smoothly.

\section{What is Knowledge Transfer?}

-Knowedge Transferll is a practical method for transitioning knowledge from one part of your business to another.

It is both a theory and a practice - which means that it can be applied to your company culture and to your business systems.

It is more than just communication, though. It involves the circulation of information, ideas, tasks, processes, tools, documents, and so much more.

\section{What Knowledge Transfer?}

Knowledge transfer is not the same as -trainingll. Neither is it simply the circulation of information (facts and data).

While it does include these things, knowledge transfer has more to do with identifying and harnessing your team members' adaptable skills and abilities to apply information.

It's also difficult to transfer personal, experiential knowledge from one person to another. So, knowledge transfer does its best to combine both the practical with the personal in order to shift team behavior and grow their skills.

\section{Why Knowledge Transfer Matters for Your Business Problem Solving}

Have you ever come up with a great idea, just to struggle to figure out how to put it down on paper?

When it comes to innovation and problem solving, it can be hard to convert abstract concepts into an actual game plan. Beyond that, you need to figure out a way to apply that idea to the task at hand.

Sharing knowledge is tricky because it involves quantifying and qualifying knowledge that exists in the mind. A knowledge transfer system helps you translate that knowledge into words, visuals, and processes that can then be shared with your team.

\footnotetext{
${ }^{14}$ Josh Brown (2019)Knowledge Transfer: What it is \& How to Use it Effectively
} 
Prof. L. A. Papakonstantinidis

Professor Emeritus in Political Economy worked at the Local Government Dept (exPresident) of the School of Management and Economics (ex Director), Technological Educational Institute, University of PELOPONNESUS

\section{A Perfectly Imperfect Approach to Problem Solving}

Knowledge transfer matters for your business because it improves innovation, collaboration, and understanding in your business. Rather than relying on facts and data to share information across departments, you're better able to paint a holistic picture of complicated concepts.

Since we are talking about knowledge - something rather intangible - this is a perfectly imperfect process. You can't get your team to read your mind... but you can get close.

\section{Uses of Knowledge Transfer}

Knowledge transfer can help your business in the following ways:

- Accelerate the accumulation and dissemination of knowledge across your organization

- Provide easy and rapid knowledge access to your team

- Eliminate time and space constraints in communications

- Stimulate associates to experience the value of sharing knowledge in providing custom-tailored service to customers

- Respect the dignity of each individual by cultivating an environment that enhances his or her professional development and recognizes each person as a valued member of a service-oriented team $^{15}$

\section{Economy of the Mind}

The cross-fertilization between economics and neuroscience $16^{16}$ has affected both fields profoundly: in fact, while understanding the cognitive and neural determinants of - mind-readingll and -empathyll is of obvious interest to economists to incorporate the sophistication of human choices in empirically- informed theories of altruism and strategizing, the use of economic models of decision making (which, for example, imply the evaluation of tradeoffs) helps neuroscientists confront human decision making with a =rational' benchmark and translate theories into simple and testable propositions (Powell 2003; Sanfey et al. 2003; Camerer, Lowenstein, and Prelec 2005). Scholars in both fields have made an extensive use of simple experimental games to explore issues as diverse as the origin of social norms, the emergence of other- regarding preferences and of perspective-taking, the way we represent our interactions with others The most fundamental solution concepts in Game Theory - Nash equilibrium, backward induction, and iterated elimination of dominated strategies - are based on the assumption that people are capable of predicting others' actions. These concepts require people to be able to view the game from the other players' perspectives, i.e. to understand others' motives and beliefs.

Economists still know little about what enables people to put themselves into others' shoes and how this ability interacts with their own preferences and beliefs. Social neuroscience provides insights into the neural mechanism underlying our capacity to represent others' intentions, beliefs, and desires, referred to as "Theory of Mind" or "mentalizing", and the capacity to share the feelings of others, referred to as "empathy". We summarize the major findings about the neural basis of mentalizing and empathizing and discuss some implications for economics ${ }^{17}$.

In recent decades, research ${ }^{18}$ in interactive decision-making has convincingly proven that individuals are not the selfish and rational utility- maximizers of standard economic models. Several new models have been proposed, some of which introduce other-regarding preferences

\footnotetext{
15 IGI-Global Ed

${ }^{16}$ Kentall Powelll “Economy of the Mind” PLoS Biology 1(3):E77 · January 2004

${ }^{17}$ Ernst Fehr and alle 2005 "The Neuroeconomics of Mind Reading and Empathy" American Economic Review 95(2):340- 345 95(2):340-345

${ }_{18}$ Patrocinio Zaragoza-Saez (University of Alicante, Spain), Enrique Claver-Cortes (University of Alicante, Spain) and Diego Quer- Ramon (University of Alicante, Spain) 2005 A Qualitative Study of Knowledge Management: The Multinational Firm Point of View IGI-GLOBAL
} 


\section{Prof. L. A. Papakonstantinidis}

Professor Emeritus in Political Economy worked at the Local Government Dept (exPresident) of the School of Management and Economics (ex Director), Technological Educational Institute, University of PELOPONNESUS

in the utility function (Rabin 1993; Fehr and Schmidt 1999), or limited cognitive capacity (Stahl and Wilson 1994, 1995; Camerer et al. 2004), and bounded rationality in various forms (Gigerenzer and Selten 2001; Crawford 2003). Although the behavioral models differ in many respects and all depart from the -rationalll benchmark, they still assume that players form sophisticated beliefs about other players' behaviors, and act consistently with these beliefs.

The recent interdisciplinary literature on -mind readingll has fostered a plethora of studies on the mechanisms and conditions that favor or impede our understanding of the thoughts and feelings of others, including the conditions that allow us to -seell a game from the vantage point of our opponent and to act moved by empathy, altruism and desire to reciprocate.

Behavioral evidence on -mind readingll in game playing is mixed: laboratory data suggest inconsistency between beliefs and choices (Costa- Gomes and Weizsacker 2008), acting as if the player has no beliefs at all (Weizsacker 2003), or -suboptimall behavior deriving from incorrect and/or simplified mental representations of the situation at hand (Devetag and Warglien 2008). Di Guida and Devetag (2012) show that when players face an interactive decision problem they have never encountered before look first for natural or obvious solutions, some of which imply -neglectingll the other player and transforming the game into an individual decision making problem, while others imply relying on focal points leading to fair outcomes.

The highest payoff sum (the so-called altruistic strategy in the behavioral literature, which in our case necessarily benefits one player more than the other, otherwise the outcome would be categorized as focal point).

We observed only minor age effects and no effect at all due to gender and presence of siblings in the family.

Overall, our results suggest that some specific characteristics of a strategic situation trigger strategic thinking and perspective taking, while others do not. -Autisticll choice heuristics (such as picking a strategy with a good risk/return profile for themselves, which can be applied in the absence of any beliefs on the other player's behavior) tend to be abandoned with age, although the differences in shares are not significant: hence, when adult players exhibit this type of strategy it may be the consequence of a conscious decision to ignore the other player's intentions and beliefs rather than of sheer inability to - readll their minds......findings also support the conjecture that fairness-based norms and preferences for equality may have developed within societies in virtue of their innate - saliencell and because they represented efficient solutions to difficult allocation problems.

Further research should explore this conjecture by testing the power of -fairll focal points across societies and cultures The social and neural sciences share a common interest in understanding the mechanisms that underlie human behaviour. However, interactions between neuroscience and social science disciplines remain strikingly narrow and tenuous. We illustrate the scope and challenges for such interactions using the paradigmatic example of neuroeconomics. Using quantitative analyses of both its scientific literature and the social networks in its intellectual community, we show that neuroeconomics now reflects a true disciplinary integration, such that research topics and scientific communities with interdisciplinary span exert greater influence on the field. However, our analyses also reveal key structural and intellectual challenges in balancing the goals of neuroscience with those of the social sciences. To address these challenges, we offer a set of prescriptive recommendations for directing future research in neuroeconomics. ${ }^{19}$

\section{Decision Making}

${ }^{19}$ Clement Levallois, John A. Clithero, Paul Wouters, Ale Smidts and Scott A. Huettel (2012) Translating upwards: linking the neural and social sciences via neuroeconomics" Nature Reviews Neuroscience | AOP, published online 4 October 2012; doi:10.1038/nrn3354 
Prof. L. A. Papakonstantinidis

Professor Emeritus in Political Economy worked at the Local Government Dept (exPresident) of the School of Management and Economics (ex Director), Technological Educational Institute, University of PELOPONNESUS

\section{Introduction}

Decision making in a social group displays two unique features. First, humans and other animals routinely alter their behaviors in response to changes in their physical and social environment. As a result, the outcomes of decisions that depend on the behaviors of multiple decision makers are difficult to predict, and this requires highly adaptive decision-making strategies. Second, decision makers may have other-regarding preferences and therefore choose their actions to improve or reduce the well-beings of others. Recently, many neurobiological studies have exploited game theory to probe the neural basis of decision making, and found that these unique features of social decision making might be reflected in the functions of brain areas involved in reward evaluation and reinforcement learning. Molecular genetic studies have also begun to identify genetic mechanisms for personal traits related to reinforcement learning and complex social decision making, further illuminating the biological basis of social behavior.

\section{Introduction}

The problem of decision making is challenging, because the future outcomes from a particular action are seldom fully predictable. Therefore, decision makers must always take uncertainty into consideration when they make choices1. In addition, such action-outcome relationships can change frequently, requiring adaptive decision-making strategies that depend on the observed outcomes of their previous choices Accordingly, neurobiological studies on decision making have focused on the brain mechanisms for mediating the effect of uncertainty and improving the decision-making strategies by trial and error. Such studies have found that signals related to reward magnitude and probability are widespread in the brain and often modulated by the active process of decision making (see other papers in this issue). Some of these brain areas might be also involved in updating the preference and strategies of decision makers.

Compared to solitary animals, animals living in a large social group face many unique challenges and opportunities, as reflected in various cognitive abilities in social domain, such as communication and other prosocial behaviors This review focuses on the neural basis of socially interactive decision making in humans and other primates. The basic building blocks of decision making that underlie the process of learning and valuation also play important roles for decision making in social contexts. However, interactions among multiple decision makers in a social group display some new features.

First, behaviors of humans and animals can change frequently, as they seek to maximize their self-interests according to the information available from their environment. This makes it difficult to predict the outcomes of a decision- maker's actions and to choose optimal actions accordingly. As a result, more sophisticated learning algorithms might be required for social decision making Second, social interactions open the possibility of competition and cooperation. Humans and animals indeed act not only to maximize their own self-interest, but sometimes also to increase or decrease the well-beings

This study ${ }^{20}$ investigates mentalizing and strategic thinking in children in elementary school age (from 7 to 12 years old). Drawing from previous literature in behavioral and experiments economics and cognitive science, we conduct experiments in which children of different ages make choices in a series of one-shot, simultaneous move two-person games in normal form. We test the ability of our subjects to reason strategically and compare their behavioral patterns with those of adult players engaged in similar tasks (Di Guida and Devetag 2012). Our results show that even younger children are capable of perspective taking: they seem to grasp the essence of strategic thinking, to recognize similarities across games, and behave consistently. In addition, children are sensitive to the attractive power of focal points (Di Guida and Devetag 2012), which

20 Theory of Mind in the Social Sciences: An Experiment On Strategic Thinking in Children Devetag Giovanna1 Di Guida Sibilla2Natalia Montinari 
Prof. L. A. Papakonstantinidis

Professor Emeritus in Political Economy worked at the Local Government Dept (exPresident) of the School of Management and Economics (ex Director), Technological Educational Institute, University of PELOPONNESUS

are perceived as natural coordination devices even when they are not part of the game equilibria, in line with previous results.

Children are also able to perceive the risk-return tradeoffs implied in strategic decisions, as shown by their preference for - safell strategies (i.e., strategies yielding an acceptable payoff for any choice of the opponent). Finally, only a minority behaves according to naive heuristics such as opting for the strategy giving the maximum payoff. Our findings contribute to the interdisciplinary literature on the origin of fairness-based norms within societies and on the cognitive and social determinants of strategic interaction.

\section{Interactive Decision Making}

Monkeys won't work for unequal pay. If a partner monkey gets a grape (big bucks) for little or no work (trading a token), a monkey will reject her measly cucumber pay from her human -boss.ll And she makes her disdain known, hurling her cucumber or token out of her cubicleeven though she would happily gobble down cucumbers in other circumstances.

De Waal's work at the Yerkes Primate Center at Emory University in Atlanta has shown an aversion to inequality in non-human primates (Figure 1), drawing an evolutionary link between how humans and monkeys make decisions. Humans reject inequality, too, even if it means walking away empty-handed. This behavior cannot be explained by classical economic theory that says both monkeys and humans should take whatever reward they are offered to maximize gain. But in species like de Waal's monkeys and humans that rely heavily on cooperation for survival, evolution has favored a complex calculus for even simple decisions.

In a simplified way, de Waal's PLoS Biology | experiments and others blend neurobiologists' ability to track behavior and brain processes with economists' models of the cost-benefit analyses behind every decision made by an animal. The two fields have each been working toward explaining decision-making behavior, using widely different approaches for decades. Recently, researchers in both fields have recognized that using tools from the other trade might speed their own work along, resulting in the emerging field of neuroeconomics

\section{Teaming Up}

The principle of Expected Utility says that a person facing uncertainty will rank the possible payoffs or outcomes as a function of their expected values and probabilities of happening. Using this principle, experimental economists tested the idea that humans should interact with a selfinterest that gives the highest possible gain. In the Ultimatum game, one person is given a sum of money and must decide how much of that sum to share with a second person. The second person can then decide to accept or reject the offer, but the catch is that if he rejects the offer, neither player gets any money.

Although rational-decision theory predicts that the first player should make a low offer and the second player should accept because it would maximize how much each player leaves with, the results were resoundingly irrational. Most first players offered close to half of the money and most second players rejected sums lower than half. Economists were stumped when their models fell far short of explaining human decision-making.

-Standard economic theory uses models where players are calculating complicated numbers, thinking far ahead to figure out what the other person will do, and there are no temptations, II explains Colin Camerer, a behavioral economist at the California Institute of Technology in Pasadena. Those models tended to be mathematically simple, but realistically hard on the players, he says. - People aren't that smart.

This is an open-access article distributed under the terms of the Creative Commons Attribution License, which permits unrestricted use, distribution, and reproduction in any medium, provided 
Prof. L. A. Papakonstantinidis

Professor Emeritus in Political Economy worked at the Local Government Dept (exPresident) of the School of Management and Economics (ex Director), Technological Educational Institute, University of PELOPONNESUS

the original work is properly cited.Camerer has teamed up with neurobiologists looking at brain scans of people while they play games like Ultimatum. The results of such experiments should reveal new mechanisms at play in the brain during decisions, like aversion to inequality, that economists can add to their models to reflect the sophistication of human choices more accurately.

On the other side of the decision-making fence, neurobiologists in the last decade had begun to look beyond mapping how the brain processed sensory input or motor output and began asking questions about what was happening in between those two systems. Once they turned away from simple experiments in which a single stimulus elicits a uniform response, giving meaning to neural activity was no longer easy. For example, Paul Glimcher and his colleagues at New York University in New York City gave monkeys a visual cue indicating that a gaze shift either to the left or right would result in some level of juice reward. All things being equal, monkeys had no reason to favor one side or the other. However, when the experimenters increased the amount of juice reward for one side on random trials, the same visual cue now elicited a very different pattern of movement, favoring that side. And the neural activity they recorded appeared to reflect the monkeys' sense of how they could get the most reward, rather than any clear association with sensation or action.

\section{The Win-Win-Win Papakonstantinidis Approach}

From the other hand, the win-win-win papakonstantinidis approach is going to incorporate intuition, as there are to different paths, leading in the same conclusions In particular, the mechanism jointed metallization with the win-win-win papakonstantinidis model

The process:

We firstly analyze the relation (if any) between bargaining and intuition: this relation defines a conditional (Bayesian) probability ${ }^{21}$ :

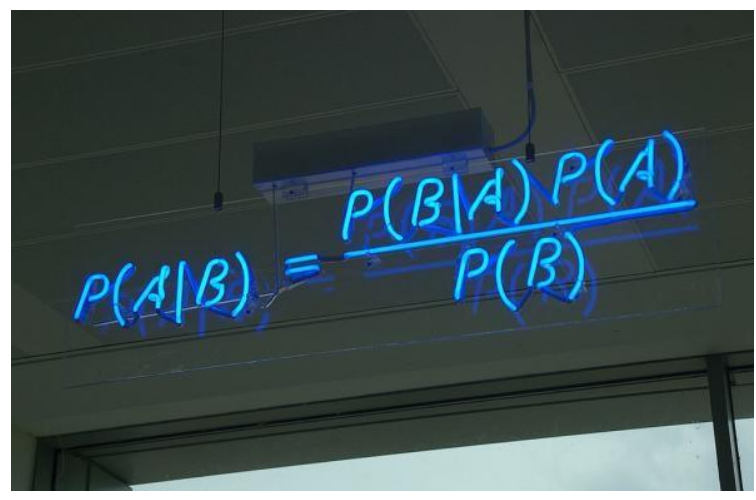

Where $A$.. and.. $B$ are events, and $P(B) \neq 0$

$P(A \mid B)$ is..a..C.P... the. likelihood ..of ..envent.. $A$,.occuring given..that..B...is..true

$P(B \mid A)$ is..a..C.P..: the. likelihood ..of ..envent.. $B, .$. occuring..given..that..A...is..true

$P(A)$..and..P(B)..are..the.. probability es.. / of ...B,..observing..A..and..B,..respektively they..are..known..as..the..ma.rginal.. probability

${ }^{21}$ In probability theory and statistics, Bayes' theorem (alternatively Bayes's theorem, Bayes's law or Bayes's rule) describes the probability of an event, based on prior knowledge of conditions that might be related to the event. For example, if the risk of developing health problems is known to increase with age, Bayes's theorem allows the risk to an individual of a known age to be assessed more accurately than simply assuming that the individual is typical of the population as a whole 


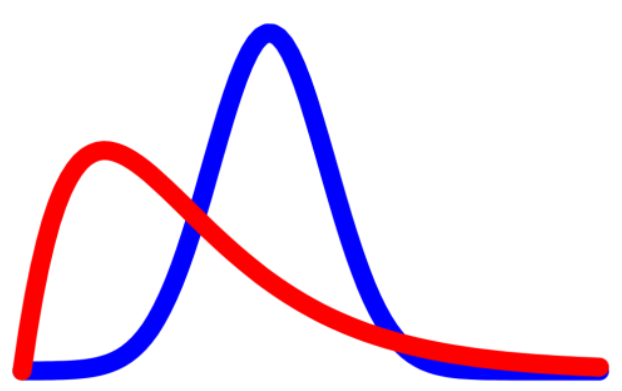

We find the likelihood of $A=$ Bargaining, given the $B=$ intuition, is true Also, we find the likelihood of intuition $A$ under the condition of bargaining $B$ is true Then, tacit knowledge and its relation (if any) with bargaining intuition Then, intuition over preferences, and, intuition over inequalities (as advantage and disadvantage cases) We summarize our conclusions on intuitions as the base of the win-win- win papakonstantinidis Finally, our Results could be useful to the other studies on intuition variable

2020/Jun

\section{Subjective and Objective Desirability an}

\section{Approach}

In economics, the subjective desirability of a particular choice is quantified by its utility function. Although the notion of utility is often linked to the state of the decision-maker's personal wealth, when people take into consideration the well-beings of other individuals, the utility function can be expanded to incorporate social preference. For example, Fehr and Schmidt31 proposed that the utility function can be modified by the decision maker's aversion to inequality. For two-player games, the first player's utility, $\mathrm{U} 1(\mathrm{x})$ for the payoff to the two players $\mathrm{x}=[\mathrm{x} 1 \mathrm{x} 2$ can be defined as follows:

$$
U_{1}(x)=x_{1}-a I_{D}-\beta I_{\mathrm{A}}
$$

where

$\mathrm{I}_{\mathrm{D}}=$ Inequalities..in..Disavantageous,...

$\mathrm{I}_{\mathrm{A}}=$ Inequalities..in...Advantageous

$$
I_{D}=\max \left\{x_{2}-x_{1}, . .0\right\} . \text { and... } I_{A}=\max \left\{x_{1}-x_{2}, . .0\right\}
$$

refer to the inequalities that are disadvantageous and advantageous to the first player, respectively. The coefficients $a \ldots$ and... $\beta$ indicate sensitivities to disadvantageous and advantageous inequalities, respectively, and it is assumed that

$$
\beta \prec \alpha \ldots \text { and.. } 0 \succ \beta \succ 1
$$

Therefore, for a given payoff to the first decision maker,

$$
x_{1}, . . U_{1}(x), \text { is.maximal.when.. } x_{1}=x_{2}
$$


Prof. L. A. Papakonstantinidis

Professor Emeritus in Political Economy worked at the Local Government Dept (exPresident) of the School of Management and Economics (ex Director), Technological Educational Institute, University of PELOPONNESUS

giving rise to the preference for equality. When the monetary payoff in the prisoner's dilemma is replaced by this utility function with the value of $\beta$ sufficiently large, mutual cooperation and mutual defection both become Nash equilibria (Fig 1c). When this occurs, a player will cooperate as long as he or she believes that the other player will cooperate as well. ${ }^{22}$
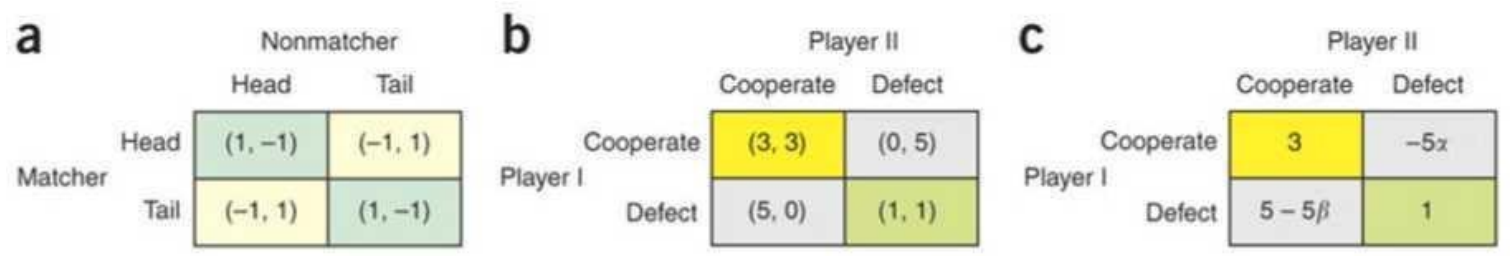

Figure 1

Payoff matrix for the games of matching pennies (a) and prisoner's dilemma (b,c). a. A pair of numbers within each parenthesis indicate the payoffs to the matcher and non-matcher, respectively, for the matching pennies game. b. A pair of numbers within the parenthesis indicate the payoffs to the players I and II, respectively, for the prisoner's dilemma game. The yellow and green rectangles correspond to mutual cooperation and mutual defection, respectively. c. The player I's utility function adjusted according to the model of inequality aversion. The values of a and $\beta$ indicate the sensitivity to the disadvantageous and advantageous inequality ${ }^{23}$

For $\beta>.0 .4$, mutual cooperation becomes a Nash equilibrium.

\section{Chapter 3 \\ 1. Introduction}

A good starting point for studies of social decision making is game theory In its original formulation, game theory seeks to find the strategies that a group of decision makers will converge on, as they try to maximize their own payoffs. Nash equilibrium refers to a set of such strategies from which no individual players can increase their payoffs by changing their strategies unilaterally In a two-player competitive game known as the matching pennies (Fig 1a), for example, each player can choose between two alternative options, such as the head and tail of a coin. One of the players wins if both players choose the same option, and loses otherwise. For the matching pennies game with a symmetrical payoff matrix as shown in Figure 1a, the Nash equilibrium is to choose both options with the same probabilities. Any other strategy can be exploited by the opponent and therefore reduces the expected payoff. A large number of studies in both humans and non-human primates found, however, that for competitive games, such as matching pennies, the predictions based on Nash equilibrium are often systematically violatedAs discussed below, this might be due to various learning algorithms used by the decision makers to improve the outcomes of their choices iteratively.

Intuition in clarify

$I_{D} \cdot$ and, $I_{A}$

\footnotetext{
${ }^{22}$ Hariri AR, Drabant EM, Weinberger DR. Imaging genetics: perspectives from studies of genetically driven variation in serotonin function and corticolimbic affective processing. Biol Psychiatry 2006;59:888-897. [PubMed: 16442081]

${ }^{23}$ Nat Neurosci. 2008 April ; 11(4): 404-409. "Game theory and neural basis of social decision making
} 
Prof. L. A. Papakonstantinidis

Professor Emeritus in Political Economy worked at the Local Government Dept (exPresident) of the School of Management and Economics (ex Director), Technological Educational Institute, University of PELOPONNESUS

A pure strategy provides a complete definition of how a player will play a game. In particular, it determines the move a player will make for any situation they could face. A player's strategy set is the set of pure strategies available to that player.

A mixed strategy is an assignment of a probability to each pure strategy. This allows for a player to randomly select a pure strategy. (See the following section for an illustration.) Since probabilities are continuous, there are infinitely many mixed strategies available to a player.

Of course, one can regard a pure strategy as a degenerate case of a mixed strategy, in which that particular pure strategy is selected with probability 1 and every other strategy with probability 0 .

A totally mixed strategy is a mixed strategy in which the player assigns a strictly positive probability to every pure strategy. (Totally mixed strategies are important for equilibrium refinement such as trembling hand perfect equilibrium.)

\section{Mixed Strategies: Illustration}

\begin{tabular}{|c|c|c|}
\hline & A & B \\
\hline A & 1, & 0,0 \\
1 & \\
\hline & 0, & 1,1 \\
& 0 & \\
B & & \\
\hline
\end{tabular}

Pure coordination game

Consider the payoff matrix pictured to the right (known as a coordination game). Here one player chooses the row and the other chooses a column. The row player receives the first payoff, the column player the second. If row opts to play A with probability 1 (i.e. play A for sure), then he is said to be playing a pure strategy. If column opts to flip a coin and play $A$ if the coin lands heads and $B$ if the coin lands tails, then he is said to be playing a mixed strategy, and not a pure strategy.

\section{Significance}

In his famous paper, John Forbes Nash proved that there is an equilibrium for every finite game. One can divide Nash equilibria into two types. Pure strategy Nash equilibria are Nash equilibria where all players are playing pure strategies. Mixed strategy Nash equilibria are equilibria where at least one player is playing a mixed strategy. While Nash proved that every finite game has a Nash equilibrium, not all have pure strategy Nash equilibria. For an example of a game that does not have a Nash equilibrium in pure strategies, see Matching pennies. However, many games do have pure strategy Nash equilibria (e.g. the Coordination game, the Prisoner's dilemma, the Stag hunt). Further, games can have both pure strategy and mixed strategy equilibria. An easy example is the pure coordination game, where in addition to the pure strategies $(A, A)$ and $(B, B)$ a mixed equilibrium exists in which both players play either strategy with probability $1 / 2$

\section{Chapter 4 \\ 1. The Intermediate Solution}

I think now, I have the material for my approach on the 3-win papakonstantinidis modelll Basically I gathered necessary material from (i) the market and (ii) the behavioral side. Also, I've identify 
Prof. L. A. Papakonstantinidis

Professor Emeritus in Political Economy worked at the Local Government Dept (exPresident) of the School of Management and Economics (ex Director), Technological Educational Institute, University of PELOPONNESUS

the basic actors of -rural community development, using the rural tourism as a toolll From the other side, the objective of the -win-win-win papakonstantinidis modell must (or may) be -conflict resolutionll, the collaboration round a local flag theme, the team psychology creation, socialization and then friendship, self-sacrifice, bravery, love, cooperation charity etc Let's see :

\section{Market Side Cournot Duopoly}

Market side: We found that (a) Perfect Competition (ideal market form) is characterized from an infinity number of providers with zero power to affect price-quantity

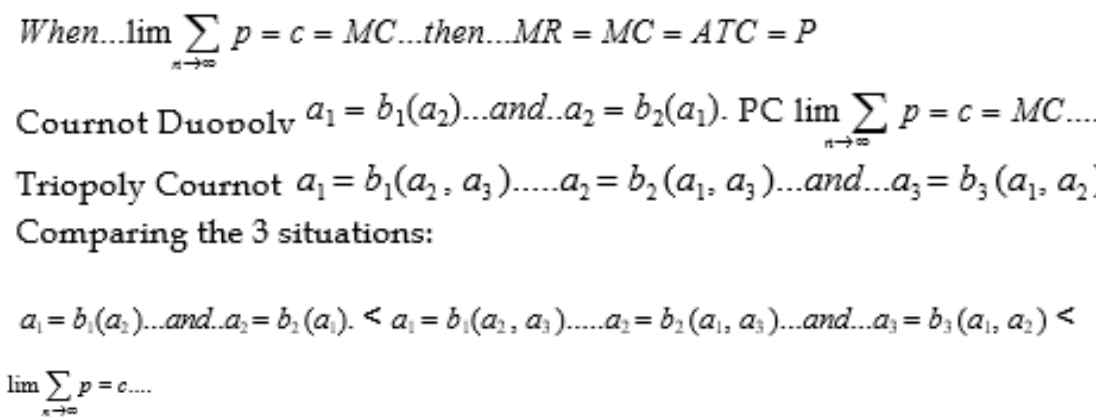

Duopoly < triopoly < perfect competition ( $\max$ social profit, $\max \mathrm{Q}$, at lowest $\mathrm{P}$ ) Theocharis (19by) proved:...

For .....n $>3 \ldots . . .\left|\lambda_{\mathrm{n}}\right|=\frac{n-1}{2}>1 \ldots .$. the ...COURNOT ...EOUILIBRIUM ...is...UNSTABLE

In terms of social welfare:

Monopoly < duopoly < triopoly < perfect competition

But (Theocharis, 1959) for $n>3$ Cournot equilibrium is unstable: -endless oscillatorll

Finally,

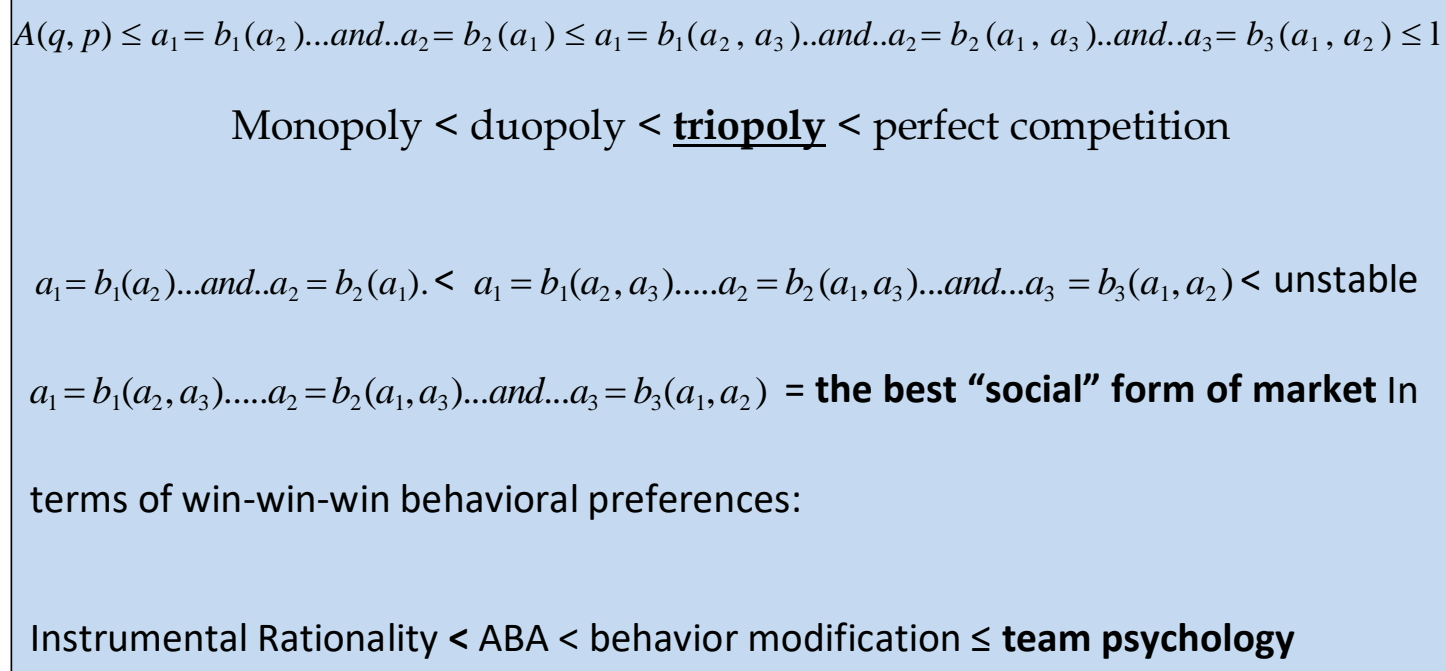

(Appendix Note 1: graph)

This means that the theoretical construction "win-win-win papakonstantinidis modelll utilizing the ABA tool, aims to differentiate the behavior of negotiators, at least, leading in -group psychology\|l 
Prof. L. A. Papakonstantinidis

Professor Emeritus in Political Economy worked at the Local Government Dept (exPresident) of the School of Management and Economics (ex Director), Technological Educational Institute, University of PELOPONNESUS

The creation of "group psychology" actually is the great prerequisite for Community Development, based in rural tourism Besides, each of the PAC members, has now, more than two possible choices with their corresponding - trinomial probability distributionll There are more free to decide and thus closer to a fair agreement Indeed, according to 3-win model in a sensitized "triopoly" there is much less likelihood injustice and inequality especially in local level, as the result of the sensitization process, thus preparing all the PAC actors be involved in the community development.

This should be done by implementing the step by step sensitization process to the ideal situation of -team psychology\|l On that point, the sensitization process stops. The -win-win-win papakonstantinidis modell corresponds 1-1 to the triangular layout of a triopoly market, and under trinomial probability distribution

\section{Building up Win-Win-Win Conceptualization}

I think, I've argued, until now, in building the win-win-win conceptualization, up to the level of its basic understanding. I've tried to approach it both, through market and behavior side focusing on -interactionll, -choice under uncertaintyll, - bargaining behaviorll etc Now, some more - details interaction game, as well as the behavioral interaction, locally (ii) Should be considered that cases, in which "players" have incomplete information, either decide otherwise than that gives them personal utility (trembling hands) These -refinements\| put by -Harsanyi (1967) and Selten (1988) the -game with incomplete information- Nature as the 3rd playerll and Reinhardt Selten(perfect equilibrium, assuming that the players, through a "slip of the hand" or tremble, may choose unintended strategies, albeit with negligible probability) (iii) two important themes, -knowledge creation" and the "flag theme" must also considered as useful tools for someone who seeks to do positive changes in the community development (iv) Besides - win- winll perception is based on each side's personal evaluation of a dispute ( $v$ )Since both sides could benefit from such a scenario (Spais, Papakonstantinidis and Papakonstantinidis, 2009), any resolutions to the conflict are likely to be accepted voluntarily ( $\mathrm{vi}$ ) The process of integrative bargaining must achieve, win-win-win outcomes, through cooperation.

As for the Harsanyi refinement (Players with incomplete Information), which the suggested model is based on, it must be denoted that Nash-Equilibrium presupposes Players with Complete Information. Sequential Games (or dynamic games) are games where later players have some knowledge about earlier actions. Complete information requires (Harsanyi J, 1967) that every player know the strategies and payoffs available to the other players but not necessarily the actions taken. Games of incomplete information can be reduced, however, to games of imperfect information by introducing -moves by the Naturell as the 3rd player of game (Harsanyi J, 1967)

The win-win-win papakonstantinidis model, is based-mainly- on Harsanyi Nash Refinement (Bayesian Analysis): According to Harsanyi J. (as the above quick review), in cases where the consistency assumption holds, the original game can be replaced by a game where nature first conducts a lottery (Harsanyi J. (1967) in accordance with the basic probability distribution, and the outcome of this lottery will decide which particular sub-game will be played. According to Harsanyi, -Naturell is considered as the -3rd player, in a sub-game with incomplete information, conditional probability - Bayesian analysis) The 3rd win or the -intermediate winll of the model also first conducts a lottery, in a game with incomplete information: First it gives the lead in possibility of realizing the general welfare Formal definition (Harsanyi, 1967), 
Prof. L. A. Papakonstantinidis

Professor Emeritus in Political Economy worked at the Local Government Dept (exPresident) of the School of Management and Economics (ex Director), Technological Educational Institute, University of PELOPONNESUS

The game is defined as: $G=\left\langle N, \Omega,\left\langle A_{i}, u_{i}, T_{i}, \tau_{i}, p_{i}, C_{i}\right\rangle_{i \in N}\right\rangle$, where

1. $N$ is the set of players.

2. $\Omega$ is the set of the states of the nature. For instance, in a card game, it canbe any order of the cards.

3. $A_{i}$ is the set of actions for playeri. Let $A=A_{1} \times A_{2} \times \ldots A_{N}$.

4. $T_{i}$ is the types of player $\mathrm{i}$, decided by the function $\tau_{i}: \Omega \rightarrow T_{i}$. So for each state of the nature, the game will have different types of players. The outcome of the players is what determines its type. Players with the same outcome belong to the same type.

5. $C_{i} \subseteq A_{i} \times T_{i}$ defines the available actions for player i of some type in $T_{i}$.

6. $u_{i}: \Omega \times A \rightarrow R$ is the payoff function for player $\mathrm{i}$

Now, we have to reproduce the Harsanyi Bayesian game's formal definition, with some difference which is the paper's contribution: introducing the -Intermediate Communityll as the 3rd imaginary part of the negotiation between 2, as well as weighting of certain variables with coefficients, it should be possible to define the suggested -win-win-win papakonstantinidis modelll

As a synthesis Nash-Harsanyi the basic -win-win- win papakonstantinidis modell (sensitized game) equation is (Papakonstantinidis, IJRCM, 2011) 
Prof. L. A. Papakonstantinidis

Professor Emeritus in Political Economy worked at the Local Government Dept (exPresident) of the School of Management and Economics (ex Director), Technological Educational Institute, University of PELOPONNESUS

$$
G^{* *}=<N, \Omega^{*},<A_{i}, u_{i}, \phi T_{i}, t_{i}, p_{i}, C_{i} \quad \text { where }
$$

1. $N$ is the set of players.

2. $\Omega^{*}$ is the set of the states of the -Intermediate Communityl, depended on local people bargaining intra-community behavior

3. $A_{\mathrm{i}}$ is the set of actions for player i. $A=A_{1} \times A_{2} \times \ldots A_{N}$.

4. $T_{i}$ is the types of player $\mathrm{i}$, decided by the function $\tau_{i}: \Omega \rightarrow T_{i}$. So for each state of the nature, the game will have different types of players. The outcome of the players is what determines its type. Players with the same outcome belong to the same type.

5. $C_{i} \subseteq A_{i} \times T_{i}$ defines the available actions for player $\mathrm{i}$ of some type in $T_{i}$.

6. $u_{i}: \Omega \times A \rightarrow R$ is the payoff function for player $\mathrm{i}$

7. $\varphi$ : INTUITION the sensitization coefficient of $\mathrm{T}_{i}$ : Each state of the Community (Nature, Local Community, Physical Environment etc) must be (according to model definition) weighted by thel $\varphi$ l appropriate sensitization coefficient of $\mathrm{T} i$, thus providing behavioral convergence towards community prevailing ethos(Friedman John, Weaver Clyde, 1979)

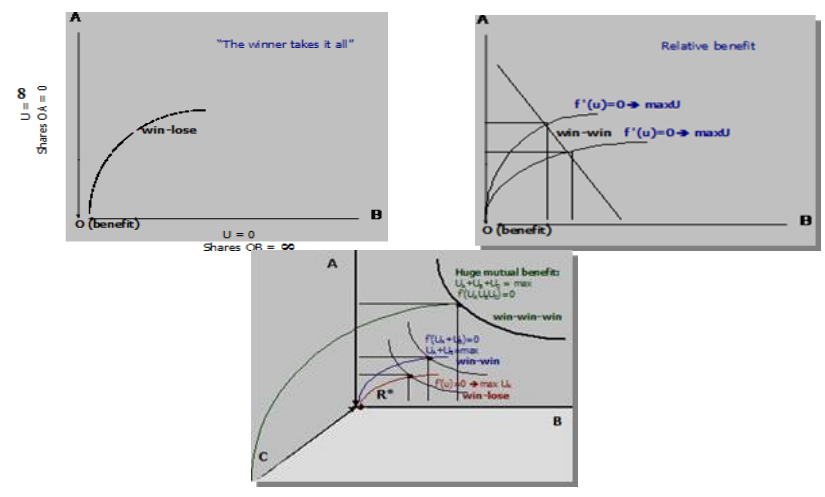

Figure 6: Win-win-win papakonstantinidis model utility functions Source: Spais, Papakonstantinidis and Papakonstantinidis (2009) 
Prof. L. A. Papakonstantinidis

Professor Emeritus in Political Economy worked at the Local Government Dept (exPresident) of the School of Management and Economics (ex Director), Technological Educational Institute, University of

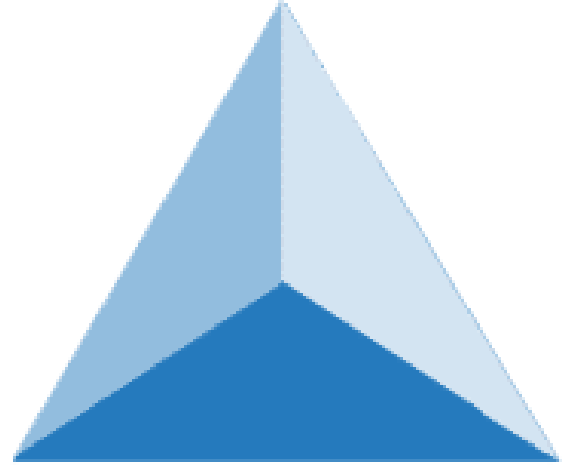

\section{Win Win-Win: from the Behavior Side}

According to Spais (Spais 2012) the win-win-win papakonstantinidis model is a methodological tool for conflict resolution, especially in the case of decision- making, or in forming "instant reflection winning strategies" in the bargain (which is the frame

From the other, - sensitization" may be concerned as an information, thus changed the 3 parts' imperfect information, into a complete information as Harsanyi's conditional probabilities claims. It is a hard process in the bargain, which smoothes the angles of conflict or the payoffs/utilities (according to Nash) The "third win" may be an umbrella, which conjoins different "dipolar relationships" Especially, in the local management context, it must be understood that the existence of a "distinguishable entity", depends upon the degree of understanding and sensitization of knowing better the other polar (Spais, Papakonstantinidis and Papakonstantinidis, 2009). For the needs of the study, I adjust the conceptualization, in order to deal with local management and development decisions The win-win-win perception is based on the assumptions of information accessibility and diffusion that characterize the modern globalized societies as well as the complexity in the decision-making values that the "third win" (the "C" factor) could unlock a series of obstacles (Spais, Papakonstantinidis and Papakonstantinidis, 2009). Another idea, is that the individual three-by-two, (although doubts) must take into consideration at each time that there is the third distinguishable part (Spais, 2012) in the bargain, based on behaviorist analysis through the "neural networks". Resent literature on behavioral analysis, provides us with the relation between knowledge and behavior So, an overview is attempt (Papakonstantinidis, 2005), as to find the relation between -knowledge transfer and knowledge creationll, in the frame of the -Modern Innovation Theory- M.I.TI (Fischer M.M, 2006 Nonaka and others) Behavior thus may resulted from this knowledge types' synthesis, as the table below

$\lim _{\rightarrow \infty} \sum$ knowledge $\rightarrow$ knowledge's..synthesis $\rightarrow$ behavior...synthesis $\rightarrow$.behavior..change $\rightarrow$ new..barg aining..conditions

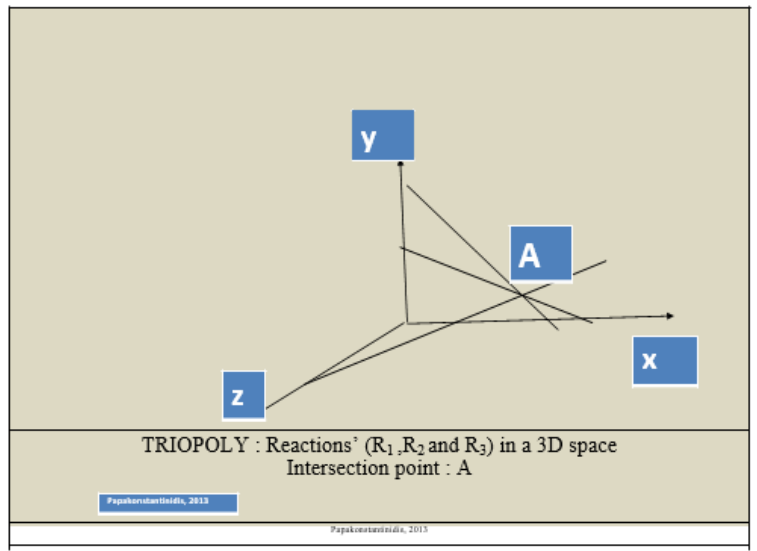


Prof. L. A. Papakonstantinidis

Professor Emeritus in Political Economy worked at the Local Government Dept (exPresident) of the School of Management and Economics (ex Director), Technological Educational Institute, University of

PELOPONNESUS

\section{Tripolar Economy}

Building a tripolar economic relation based on the sensitization process, it has been acceptable, as a -social needll: According to the suggested model, strengthening of the third "win" in an extending "non cooperative win-win game" situation leads to a new bargaining behavior, which is step by step born locally Triopoly seems to empower the -intermediate position, or the

3rd win, for the reasons that : (a) According to Cournot Theorem,

$$
\lim _{N \rightarrow \infty} p=c
$$

This situation reflects the Principles of the Absolute Competition (the invisible Hand of the Market /Adam Smith, 1760) of maximizing the social justice (higher production in the lowest price) and so the social welfare: The maximum potential amount of goods at lower price approaching marginal cost of production ( $P=M C=M R$ ), but (b) Theocharis (1959) pointed out that an oligopoly system with $n$ players would be only neutrally stable for three players $(n=3)$ and unstable for four and more players: (c) Combining (a), (b)

-triopoly\|l seems to be the best market toward social welfare and at the same time is a more realistic market Each of the 3PAC seeks to maximize individual profit, but, at the same time, each of them has more little power (in comparison with duopoly -2 competitors) to affect this market, even if it is based on the "best responses" philosophy. That means, more production, less prices, less possibility to make coalitions or collusions, more transparency Furthermore, in the suggested model, each of the three, making choices under uncertainty, has more probability for expectations of success:

Each of them has three possibilities (instead of 2) on each trial, thus forming the utility function: $u\left(c_{1}, c_{2}, c_{3} p_{1}, p_{2}, p_{3}\right)=p_{1} c_{1}+p_{2} c_{2}+p_{3} c_{3}$

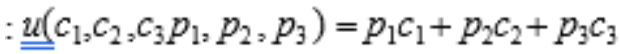

The win-win-win papakonstantinidis model is (a) a methodological tool for conflict resolution, especially in the case of decision-making, (b) a -pathll to social justice, (c) the basic process for sensitizing local population on the development, around a local -flag themell (d) a way to -feel freell through involvement in the development process (e) to develop - newll bargaining behavior (f) to convert conflict into cooperation. (g) As the sensitization process tends to infinity, then the limit of PAC relations tend to the absolute collaboration. That's the end of the real development process

$\lim _{\text {sen } \rightarrow \infty}$ P.A.C...r = absolute..collaboration

Finally, I wonder _if and under what conditions, the -win-win-winll approach (locally, at least) should in a position to face the classical - Impossibility Theoremll (Kenneth Arrow, 1951) and thus to produce social welfare During the 50s Kenneth Arrow, argued that there is no - social welfarell, as there is no -social consciencell as there is no rank-order voting systems, for the reasons that (a) If every voter prefers alternative $X$ over alternative $Y$, then the group prefers $X$ over $Y$ (b) If every voter's preference between $X$ and $Y$ remains unchanged, then the group's preference between $X$ and $Y$ will also remain unchanged (even if voters' preferences between other pairs like $X$ and $Z, Y$ and $Z$, or $Z$ and $W$ change) (c) There is no "dictator": no single voter possesses the power to always determine the group's preference. Despite its accessibility, I think that there is only one case (in the conceptual level), of not applicable. In a pure theoretical 
Prof. L. A. Papakonstantinidis

Professor Emeritus in Political Economy worked at the Local Government Dept (exPresident) of the School of Management and Economics (ex Director), Technological Educational Institute, University of PELOPONNESUS

situation this will be done: The limit of the "win-win-win papakonstantinidis model" as the sensitization process tends to infinity, is the ultimate collaboration. In that ideal case, $X=Y=Z=W$ That's the end of the -win-win-win papakonstantinidis modelll Even if impossible to go to the end, this model provides the PAC members with a direction toward community development due to rural tourism This is not a wish It is a goal, It's life. We owe it to the next generation

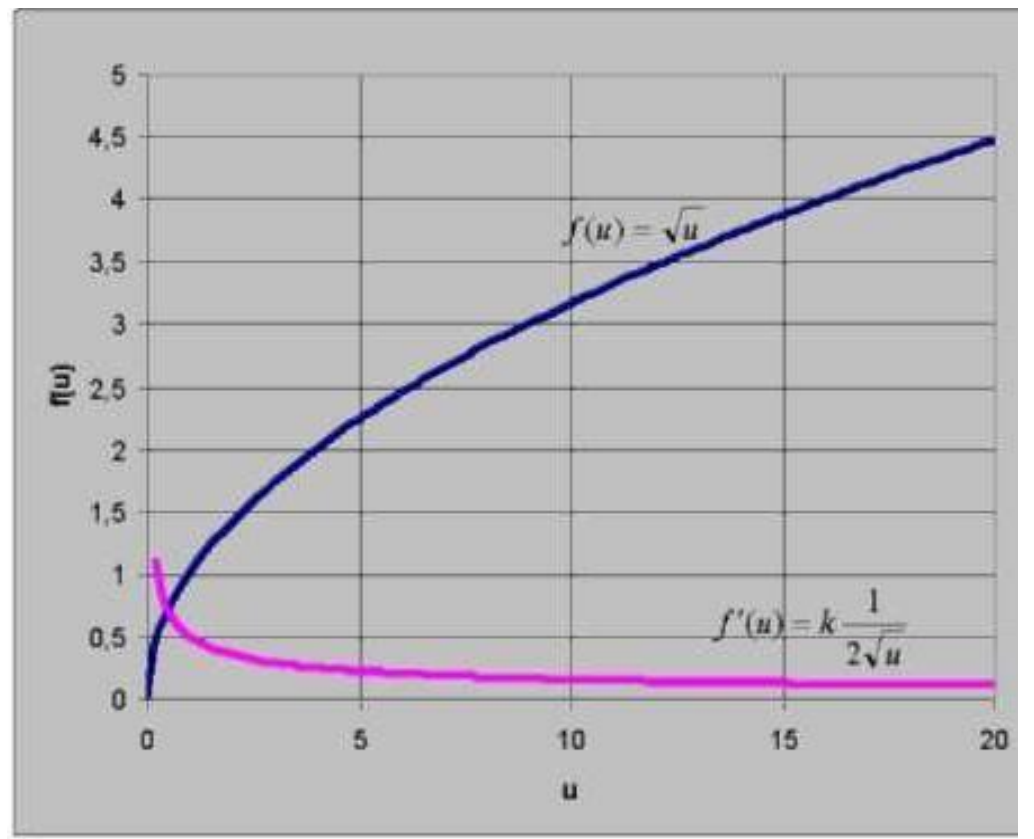

\section{Approach}

\section{Disagreement Point}

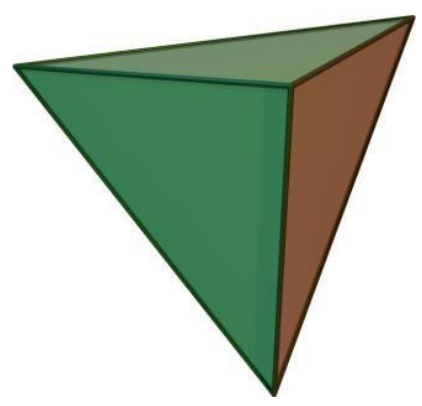

\subsection{A Definitions}

The disagreement point $d$ is the value the players can expect to receive if negotiations break down $24^{24}$. This could be some focal equilibrium that both players could expect to play. This point directly affects the bargaining solution, however, so it stands to reason that each player should attempt to choose his disagreement point in order to maximize his bargaining position. Towards this objective, it is often advantageous to increase one's own disagreement payoff while harming the opponent's disagreement payoff (hence the interpretation of the disagreement as a threat). If threats are viewed as actions, then one can construct a separate game wherein each player

24 Zeuthen, Frederik (1930). Problems of Monopoly and Economic Warfare.

- $\quad$ Nash, John (1953-01-01). "Two-Person Cooperative Games". Econometrica. 21 (1): 128-140.

- $\quad$ Rubinstein, Ariel (1982-01-01). "Perfect Equilibrium in a Bargaining Model". Econometrica. 50 (1): 97-109. 
Prof. L. A. Papakonstantinidis

Professor Emeritus in Political Economy worked at the Local Government Dept (exPresident) of the School of Management and Economics (ex Director), Technological Educational Institute, University of PELOPONNESUS

chooses a threat and receives a payoff according to the outcome of bargaining. It is known as Nash's variable threat game $25^{25}$

Disagreement point

The disagreement point $d=\left(d_{1}, d_{2}\right)$ is the value the players can expect to receive if negotiations break down. This could be some focal equilibrium that both players could expect to play. This point directly affects the bargaining solution, however, so it stands to reason that each player should attempt to choose his disagreement point in order to maximize his bargaining position.

Equilibrium Analysis

Strategies are represented in the Nash demand game by a pair $(x, y) x \ldots$ and ...y are selected from the interval $[d, z]$ is the disagreement outcome and $Z$ is the total amount of good. If:

$x+y . . i s . . e q u a l . . t o \ldots o r . l e s s . . t h a n . . . z \ldots t h e . . .1$ st ...player..recieves...x..and...the...2nd...y otherwise...both...get...d...often...d =0

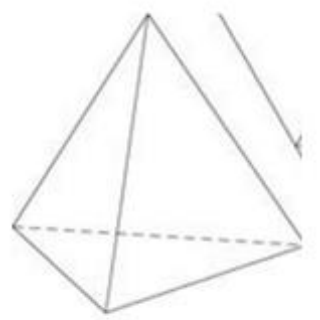

A

In bargaining theory, a -disagreement pointll or -threat pointll is the policy which is implemented if no agreement is reached. Typically, it is bad for both sides, but may be worse for one. The disagreement point has a profound impact on the outcome of negotiations, even if it never comes to pass. (In theory-land, say in Nash or Rubinstein bargaining, there is never disagreement, but the threat of disagreement is a crucial determinant of the outcome.)

Analysis

${ }^{25}$ Nash, John (1950). "The Bargaining Problem" Econometrica 18 (2): 155-162 
Prof. L. A. Papakonstantinidis

Professor Emeritus in Political Economy worked at the Local Government Dept (exPresident) of the School of Management and Economics (ex Director), Technological Educational Institute, University of PELOPONNESUS

Analysis

The two person bargaining problem consists of a pair $(F, v)$ where $F_{\text {is }}$ called the feasible set and $v$ is called the disagreement point.

- $F$, the feasible set of allocations, is a closed, convex subset of $R^{2}$

- Ihe disagreement point $v=\left(v_{1}, v_{2}\right) \in K$ represents the disagreement

payoff allocation for the two players. It is also called the status-quo point or the default point. This gives the payoffs for the two players in the event that the negotiations fail. It may be noted that $\mathrm{v}$ is invariably chosen to belong to the feasible set $F$ though it is not a mandatory technical requirement.

- The set $F \cap\left\{\left(\underset{1}{x} x_{2}\right) \in R^{2}: x_{1} \geq v ; x \geq v\right\}$ is assumed to be non-empty and bounded.

\section{Justification for the Assumptions}

- $F$ is assumed to be convex. This can be justified as follows. Assume that the players can agree to jointly randomized strategies (correlated strategies). Consequently, if the utility allocations $x=\left(x_{1}, x_{2}\right)$. and.. $y=\left(y_{1}, y_{2}\right)$. are. feasible...and ... $0 \leq a \leq 1$

planning to implement $x$ with probability $a$ and to implement. $y$ with probability $(1-a)$

- $F$ is assumed to be closed (that is, any convergent sequence in $F$ will converge to a point that belongs to $F$ ). This is a natural topological requirement. If we have a sequence of allocations belonging to $F$ and the limiting allocation does not belong to $F$, then we have an undesirable

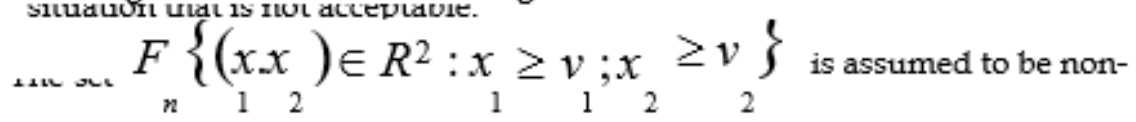
empty and bounded. This assumption implies that there exists some feasible allocation that is at least as good as disagreement for both players, but unbounded gains over the disagreement point are not possible. Both these requirements are reasonable.

\section{Utility and Disagreement Functions: the Win- Win-Win Equilibrium}

\subsection{Introduction}

Players develop their strategies in any interactive decision, behavior, thinking and living Basically, there are two interactive actions"

A. people form behaviors within the bargain based on personal, family, moral and even knowledge B. People are gradually acquiring more permanent behaviors, ethical, transactional customs, from the Bargain, gradually passing on their thinking. For this reason we are referring now to the market society 26 and not the market of the society ${ }^{26}$, that means a market integrated into society

- During the bargain, individuals develop ethics and generally behavior that influence their life

- At any bargain, disagreement (or threat) point has a crucial role:

${ }^{26}$ A society based around a market economy, especially one in which political and economic life are dominated by ideas of individual freedom and self-interest. https://www.lexico.com/en/definition/market_society 
Prof. L. A. Papakonstantinidis

Professor Emeritus in Political Economy worked at the Local Government Dept (exPresident) of the School of Management and Economics (ex Director), Technological Educational Institute, University of PELOPONNESUS

i. in a market society, disagreement point $d$ is the value the players can expect to receive if negotiations break down

ii. in a social bargain, disagreement point $d$ denotes the value the players can expect to receive if negotiations break down AND the frames of the 2 bargainers" ethics

players..A....and....B strategies / choices

(each..of ...them,...with..his / her...own..DISEGREEMENT ..POINT..d1,. d2

Social..behavior : DISAGREEMENT .(or...threat )..POINT..

beyond ....individual...disegreement...

$$
\begin{aligned}
& (u(x)-u(d)) \text {.. and } \\
& (v(y)-v(d)) \square \text { ployers, } A, B \text {.try.to. } \max \text {..x..and.y } \\
& \max \ldots \text { profit... }=. \max U_{A} \cap U_{B}=\max U_{A} \times U_{B} \Rightarrow \frac{d}{d u} f=0
\end{aligned}
$$

\section{Analysis}

- In all bargains, there is usually a set $\mathrm{S}$ of alternative outcomes and both parties must agree on some element of this set. Once an agreement is reached, the negotiation ends and both sides can get their respective returns. If they do not reach an agreement, the result is usually the status quo. So if $(t 1, t 2)$ are the odds of a point of disagreement, then the interesting part of $\mathrm{S}$ consists of those outcomes that give both sides odds greater than those of the odds. So we can define a trading problem as follows

- A two person bargaining problem (or game) consists of two people or players 1 and 2, a set $\mathrm{S}$ of alternative outcomes, and a utility function $\mathrm{u} 1$ on $\mathrm{S}$ for each player $\mathrm{i}$, so that:

$$
u_{1}(s) \geq t_{1} \quad u_{2}(s) \geq t_{2}, \ldots, \forall s \in S
$$

$\mathrm{U}(\mathrm{x}), . . \mathrm{v}(\mathrm{y}) . . \mathrm{C}(\mathrm{z})$.. are. .utility .. function, ...of ..the...b arg ainers, $\mathrm{A}$ -

B..ande..the..COMMUNITY..(C)

AND

$\mathrm{U}\left(\mathrm{d}_{1}\right), . . \mathrm{v}\left(\mathrm{d}_{2}\right), . . \mathrm{C}\left(\mathrm{d}_{3}\right) \ldots$ are. .their . .disagreement - or..threat - functions

then,

$u(x)-u\left(d_{1}\right)$

$v(y)-v\left(d_{2}\right)$

$C(z)-C\left(d_{3}\right)$

form..a..new.. function ..of ..difference s..i.e....

$$
u\left(\delta_{1}\right), v\left(\delta_{2}\right), \ldots C\left(\delta_{3}\right)
$$


Prof. L. A. Papakonstantinidis

Professor Emeritus in Political Economy worked at the Local Government Dept (exPresident) of the School of Management and Economics (ex Director), Technological Educational Institute, University of PELOPONNESUS

- Each of them defines the margin between utility (or grade of satisfaction) AND their disagreement point

$$
\begin{array}{ll}
\text { In the case of } & \begin{array}{l}
u\left(\delta_{1}\right)=0 \\
v\left(\delta_{2}\right)=0, \ldots \\
C\left(\delta_{3}\right)=0
\end{array} \text { that means } \\
u(x)-u\left(d_{1}\right)=0 \\
v(y)-v\left(d_{2}\right)=0 \\
C(z)-C\left(d_{3}\right)=0
\end{array}
$$

that. .characterize...unelasic...societies ..

with.. fixed .. preferences..and..relations

In the case of $u(\delta) \approx 0$..or..near..to..a..fixed .price, (that means, the

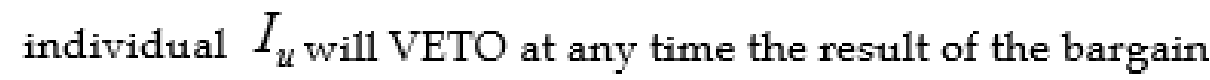
does not exactly satisfy his/ her own preferences) there is no room for social sensitivity, or even better, the $I_{u}$ individual does not let any margin for -social bargainingl

$\checkmark$ The farther away from the level of personal $u(x), . . v(y)$ and the social satisfaction $C(z)$ the point of disagreement / threat of disruption to negotiations, far is the more degrees of freedom there are in the negotiation and the greater the probabilities of agreement.

$\checkmark$ This is all the more so if the parties are three (including the Community as the third and catalytic power in the negotiation:

a. the community works for both parties as a point of reference eg the legal framework of the contracts

b. The community "requires" its own "satisfaction" which coincides with the satisfaction of the general population of the community

c. overall satisfaction is divided into three and not two parties, so the hot decision-making pressure is less and more balanced

d. New data are put on covering the "claims" and perspectives of the three-and not two-parties of the negotiation

e. avoid collusion, which may be easier in negotiations between 2 and not the three parties

f. It is not accidental that powers in a democratic society are divided between legislative, executive, and judicial powers. 
Prof. L. A. Papakonstantinidis

Professor Emeritus in Political Economy worked at the Local Government Dept (exPresident) of the School of Management and Economics (ex Director), Technological Educational Institute, University of PELOPONNESUS

$\mathrm{g}$ the inclusion of the community in the win-win-win-win [as social cohesion, as a moral, as a culture, but also as a whole of its population] and not as a court, is based on its actual immediate interest which is the interest of many who may not are directly involved in the bargain

$\mathrm{h}$. The tendencies that develop in such a trilateral negotiation thus form a "memory" state (something like court jurisprudence, or "good business ethics"): The difference here is that many forces are mobilized that shape a flexible behavior and not a strict relation established by case law

\section{Chapter 6: Social Bargaining in Terms of Disagreement ${ }^{27}$ 3-Ple Equilibrium Ideal situation-the Angels' Moment}

$\checkmark$ It is obvious that in a Democratic Society, must be

$$
\begin{array}{lc}
u(x)-u\left(d_{1}\right)=m \cdot a x & u\left(d_{1}\right)=0 \\
v(y)-v\left(d_{2}\right)=m \cdot a x & \begin{array}{l}
v\left(d_{2}\right)=0 \text { the Angels MOMENT } \\
C(z)-C\left(d_{3}\right)=m \cdot a x
\end{array} \\
C\left(d_{3}\right)=0
\end{array}
$$

$\checkmark$ The maximum profit for the society is

$$
\begin{aligned}
& \operatorname{mox}\left(u(x)-u\left(d_{1}\right)\right)\left(v(y)-v\left(d_{2}\right)\right)\left(C(z)-C\left(d_{3}\right)\right) \\
& \operatorname{mox}(u(x)-u(t))(v(y)-v(t))(C(z)-C(t))
\end{aligned}
$$

Or, in threat terms:

- In a poetic expression, people have to set higher goals, in every interaction - negotiation so they can express their disagreement, at some point or threat point of stopping the negotiation

- in an even more poetic expression, people must re-start dreaming of a better life again - one of the signs of globalization is to level everything for instant euphoria

- but so have people stopped dreaming ... Relationships, expectations, products and even lasting products (furniture- kitchens etc) and even the heads of state and government and relationships between them have all become instant (1)

- The deep wound of globalization is the conversion of everything from constant to instant

- People have to accept this -instant pointll, without history, future, and without dreams Ignatius Ramonet supports - and not unfairly - - ...the past - present and the future has been squeezed into the instant now, the supreme moment of history

- ...... all made by the wish factory2828. "- 1000 cold -NOIl for an emotional -YESII Buskalia

- Of course, every citizen has (at least theoretically the right of veto, a veto

$$
\begin{aligned}
& \forall u \in S_{i}(u-t), \exists t_{i}^{*}, \text { so.that } \ldots\left(u_{1}-t_{1}\right)<\left(u_{2}-t\right)<\ldots<\left(u-t_{i}^{*}\right) \\
& t=\text { veto, or..democracy.. perception }
\end{aligned}
$$

Papakonstantinidis 2019

27 PAPAKONSTANTINIDIS LA , 2002

${ }^{28}$ Ignacio Ramonet:

- $\quad 1989$ : La Communication victime des marchands

- 1996 : Nouveaux pouvoirs, nouveaux maîtres du monde (French: New Powers, New World Masters) 
Prof. L. A. Papakonstantinidis

Professor Emeritus in Political Economy worked at the Local Government Dept (exPresident) of the School of Management and Economics (ex Director), Technological Educational Institute, University of PELOPONNESUS

Angels '..Society

$\operatorname{MAX} . .\left(u-t_{1}\right)\left(u_{-}-t_{2}\right)\left(u_{3}-t\right) \rightarrow\left[\left(u_{1}-t\right)\left(u_{2} t\right)\left(u_{-} t\right)\right]^{\prime}=0$

$\left(u_{1}-t_{1}\right)=M A X$

$\left(u_{2}-t_{2}\right)=M A X$

$\left(u_{3}-t_{3}\right)=M A X$

$u_{i}$ : utility ...ex. pectation

t : ..the..value..the.. players..can..ex.

pect..to..recieve if ..negotiatio n..break. .down

$$
\begin{aligned}
& t_{1} \rightarrow 0 \\
& t_{2} \rightarrow 0 \\
& t_{3} \rightarrow 0
\end{aligned}
$$

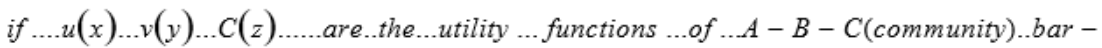

genre $s$, then

$$
\max (u(x)-u(d))(v(y)-v(d))(C(z)-C(d))
$$

The win-win-win papakonstantinidis model

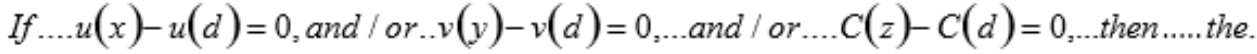

.multiplication.. product...will...be ...also...ZERO..

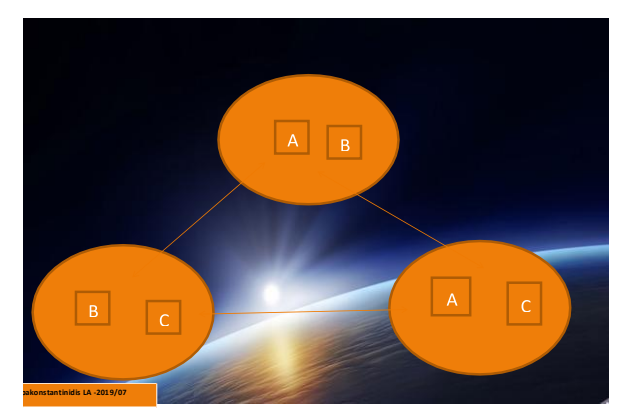

Papakonstantinidis 2010

the win-win-win papakonstantinidis model 19

Each of the three taking part in a bargain prevents possible collusion of the other two 
Prof. L. A. Papakonstantinidis

Professor Emeritus in Political Economy worked at the Local Government Dept (exPresident) of the School of Management and Economics (ex Director), Technological Educational Institute, University of

PELOPONNESUS

\section{A. THE SHARING/PROBABILITY PROBLEM IN MIXED STRATEGIES}

\begin{tabular}{|c|c|c|c|c|}
\hline Share & Share & Utility & Utility & Utility \\
\hline $\boldsymbol{( \% )}$ & $\boldsymbol{B}$ & $\boldsymbol{A}$ & $\boldsymbol{B}$ & $\boldsymbol{A X \boldsymbol { B }}$ \\
\hline 100 & $\mathbf{( \% )}$ & & & \\
\hline 90 & 10 & 0 & 83 & 0 \\
\hline 80 & 20 & 1 & 78 & 78 \\
\hline 70 & 30 & 5 & 70 & 350 \\
\hline 60 & 40 & 10 & 68 & 680 \\
\hline 50 & 50 & 23 & 60 & 960 \\
\hline 40 & 60 & 31 & 52 & 1196 \\
\hline$\underline{\mathbf{3 0}}$ & $\underline{\mathbf{7 0}}$ & $\underline{\mathbf{4 0}}$ & 50 & 1550 \\
\hline 20 & 80 & 55 & $\underline{\mathbf{4 4}}$ & $\underline{\mathbf{1 7 6 0}}$ \\
\hline 10 & 90 & 70 & 30 & 1650 \\
\hline 0 & 100 & 81 & 18 & 1260 \\
\hline & & & 0 & 0 \\
\hline
\end{tabular}

Non-cooperative coalition theory considers this interesting aspect of negotiation processes and, without making any assumption on the final result, analyzes the incentives that players may have to form coalitions, and how the incentives may affect the final outcome of the negotiation. The study of coalition formation is particularly important in bargaining contexts where positive externalities are present. In this case, due to players" incentive to free ride, it is quite unlikely that a "grand coalition" will form; instead "partial agreements" usually arise.

Finally, traditional models of negotiation have focused almost exclusively on the efficiency properties of both the process and the outcomes. Yet, as every day experience indicates, considerations other than efficiency play a crucial role in selecting which agreement will be reached - if any at all - and through which path. The theory of fair division focuses on processes and strategies that respond not only to Pareto efficiency, but also to equity, envy-freeness, and invulnerability to strategic manipulation $29 .{ }^{29}$

${ }^{29} 29$ The Policy Research Working Paper Series disseminates the findings of work in progress to encourage the exchange of ideas about development issues. An objective of the series is to get the findings out quickly, even if the presentations are less than fully polished. The papers carry the names of the authors and should be cited accordingly. The findings, interpretations, and conclusions expressed in this paper are entirely those of the authors. 
Prof. L. A. Papakonstantinidis

Professor Emeritus in Political Economy worked at the Local Government Dept (exPresident) of the School of Management and Economics (ex Director), Technological Educational Institute, University of PELOPONNESUS

The "Sharing problem" in a Bargain [Utilities, Shares, strategies, decision- choices, behaviour, Final Agreement]

Having defined: (1) How information resulting from "knowledge creation /knowledge transfer" should contribute to what we call "social market" (2) How sensitization should be introduced to given information, as to turn it to an integrated information (Papakonstantinidis, 2006) (3) How "integrated information" should influence human behaviour during the bargain, or negotiations (4) How a human "social" behaviour could lead to a "new" perception of thinking or taking a decision, in the bargain (see at Calvert Randall, 1995, Berger, J 2005 Cinneide M. O“ 1991, Coleman J 1988, Yitzak Samuel 1997, Bernheim Douglas B. 1984 (5) How socialization could influence human choices or winning strategies during the bargain, based on instant reflection (Nash) (6) How scientific thought could transfer the problem from "utilities" (personal perception") to pay-offs (objective perception = counting size) Harsanyi John(1973), then, the data of Table 2 may be transformed in a new set of data, as Table 3.

Table 3: (Papakonstantinidis Proposal) Suggesting Sharing between "A , "B" and "C"

\begin{tabular}{|c|c|c|c|c|c|c|c|}
\hline $\begin{array}{l}\text { Share A } \\
\text { (\%) }\end{array}$ & $\begin{array}{l}\text { Share B } \\
(\%)\end{array}$ & $\begin{array}{l}\text { Utilit } \\
\boldsymbol{y} \underline{A}\end{array}$ & $\begin{array}{l}\text { Utilit } \\
y \underline{B}\end{array}$ & $\begin{array}{l}\text { Utilit } \\
y \\
A X B\end{array}$ & $\begin{array}{l}\text { Share C } \\
(\%)\end{array}$ & $\begin{array}{l}\text { Utilit } \\
y C\end{array}$ & $\begin{array}{l}\text { Utility } \\
\text { AXBXC }\end{array}$ \\
\hline 90 & 4 & 1 & 71 & 71 & 6 & 1 & 71 \\
\hline 80 & 13 & 2 & 70 & 140 & 7 & 2 & 280 \\
\hline 70 & 22 & 5 & 68 & 340 & 8 & 3 & 1020 \\
\hline 60 & 31 & 10 & 64 & 640 & 9 & 4 & 2560 \\
\hline$\underline{50}$ & $\underline{40}$ & $\underline{16}$ & $\underline{60}$ & $\underline{960}$ & $\underline{10}$ & $\underline{5}$ & $\frac{4800}{\max }$ \\
\hline 41 & 50 & 23 & 52 & 1196 & 9 & 4 & 4784 \\
\hline 32 & 60 & 31 & 40 & 1240 & 8 & 3 & 3720 \\
\hline 23 & 70 & 40 & 24 & 960 & 7 & 2 & 1920 \\
\hline 14 & 80 & 50 & 12 & 600 & 6 & 1 & 600 \\
\hline
\end{tabular}

(Papakonstantinidis Proposal)

Notes, as to explain the symbols:

- "C" expresses the Community (an acceptable system value at local level), as the "third" or invisible part in the bargain. In real terms, it reflects the "confidence indicators", or, in other words, if and at which level each member of the Community trusts the other, during the bargain (H. Hans 1997)

- The less shares for $A+B$ the more share for " $C$ " part

- Utility is a personal matter: Utility units are not compared to each other. They express the fear of breaking down the agreement

- If " $\mathrm{A}$ " needs more the "agreement" than the payoff, then he should be ready to accept any form of agreement.

Utility function: Law of diminishing marginal returns (or costs)

We start from an economic-math principle: the law of diminishing marginal returns goes by a number of different names, including law of diminishing returns, principle of diminishing marginal productivity and law of variable proportions. This law affirms that the addition of a larger amount of one factor 
Prof. L. A. Papakonstantinidis

Professor Emeritus in Political Economy worked at the Local Government Dept (exPresident) of the School of Management and Economics (ex Director), Technological Educational Institute, University of PELOPONNESUS

of production, while all others remain constant, identified by the Latin term "ceteris paribus," inevitably yields decreased per-unit incremental returns.

Two "concepts" for the utility:

1. The cardinal utility concept: is concerns the idea of a measured quantitatively, like length, height, weight, temperature, etc

2. The ordinal utility concept: expresses the utility of a commodity in terms of "less than" or "more than" in individual scale of preferences

As each tries to maximize his/her own utility function (the "personal ordinal", not been measured as the cardinal) knows that more and more quantities over a point that he/she maximizes his/her satisfaction in personal terms, the less satisfaction from these more and more quantities. The derivative of a function of a real variable measures the sensitivity to change of a quantity (a function value or dependent variable) which is determined by another quantity (the independent variable). Derivatives are a fundamental tool of calculus.

From this "RULE" a crucial condition happens:

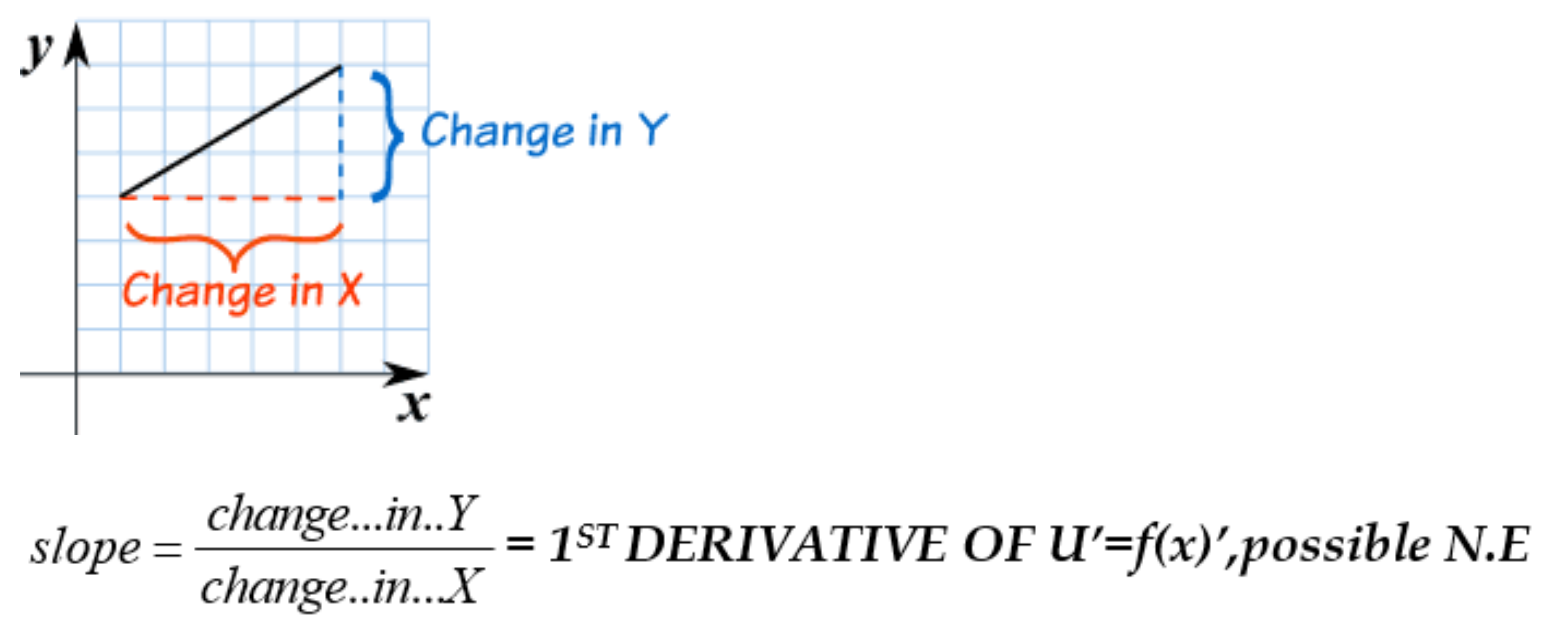

\section{The "win-win-win Equilibrium"}

From the two graphs above, and the "Pareto Efficiency" conditions is resulted that the "utility functions" follows the law of diminishing marginal returns, The law of diminishing marginal returns, includes the marginal productivity and law of variable proportions (Turgot (17271781)

$$
\begin{aligned}
& \text { It is If ..u } u=f(x) . . i s . . \text { a..utility .. function ,..then.. } \frac{d(f(x))}{d x} \text {, or.. } \\
& f(x)^{\prime} \text {..is..its..MARGINAL...UTILITY .... FUNCTION }
\end{aligned}
$$


Prof. L. A. Papakonstantinidis

Professor Emeritus in Political Economy worked at the Local Government Dept (exPresident) of the School of Management and Economics (ex Director), Technological Educational Institute, University of PELOPONNESUS

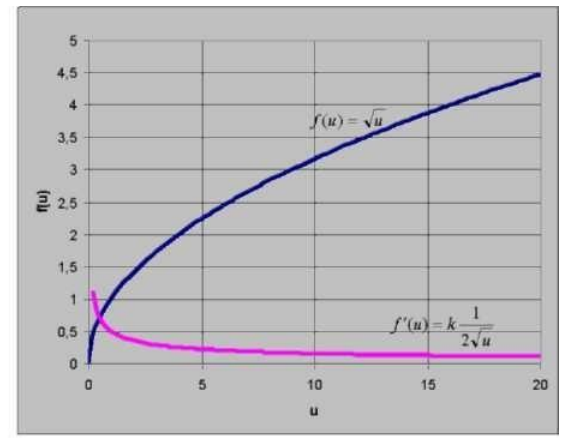

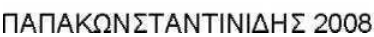

As..the.."rational....individual....objective.... is..to....MAXIMIZE..individual ..... profit then, on. .the..MAX ..POINT...in..his / her...Utility .. function ,..the.aditional / $\mathrm{m}$ arg inal ..quantity ..must..be..zero..or..in..the..neghiborhood..of ...ZERO

1. It..is...assumed..that. .the....MAX ..Utility .. function.. for.... all.. people.. $\Rightarrow$ MARGINAL..UTILITY = ZERO,

If ....U $A, U_{B}, U_{C}$..are..UTILITY..FUNCTIONS..of ...A, ..B,..AND..C,..then..the.. product..U $A * U_{B}$ $* U_{C}$

responds.."social..welfare"..So....if ..the.. product.......U $A * U_{B} * U_{C}=$ MAX ..then.. MRS =

0 ..that ' s..the..END..of

the..development... process..(IDEAL...CASE

)..We..can..measure..the..result..in..terms..of ..deviation.. from

ideal..case...The.."win - win - win.. papakons tantinidis .."EQUILIBRIUM

'Pareto Efficiency'

Pareto efficiency, also known as "Pareto optimality," is an economic state where resources are allocated in the most efficient manner, and it is obtained when a distribution strategy exists where one party's situation cannot be improved without making another party's situation worse. Pareto efficiency does not imply equality or fairness.

$$
\begin{aligned}
& \sum p_{i} x_{i} \leq M, \ldots \forall x_{i} \geq 0, \ldots \forall x_{i} \in\{1, . .2, . . n\} \\
& p=\text { price }, \ldots x_{i}=q u a n t i t i e s . . . . \sum p x_{i}=\text { sum..of ..all, }, p x_{i} \\
& M=\text { FRONTIER...MAX..sources.. for..allocation }
\end{aligned}
$$

$$
\begin{aligned}
& U_{i}=u_{i} \times p_{i} \\
& U_{A}=u_{A} \times p_{A} \\
& U_{B}=u_{B} \times p_{B} \\
& U_{C}=u_{C} \times p_{C}
\end{aligned}
$$

$\mathrm{U}=$ pleasant. . exp eriance...according..to....a..strictly.. personal... positive..list

$\mathrm{u}=$ individual utils..(not..measuring)

$p=$ probabilities, these.. pleasant... exp eriance' s..utils..to..occure..in..the...A.B.C..individuals 
Prof. L. A. Papakonstantinidis

Professor Emeritus in Political Economy worked at the Local Government Dept (exPresident) of the School of Management and Economics (ex Director), Technological Educational Institute, University of PELOPONNESUS
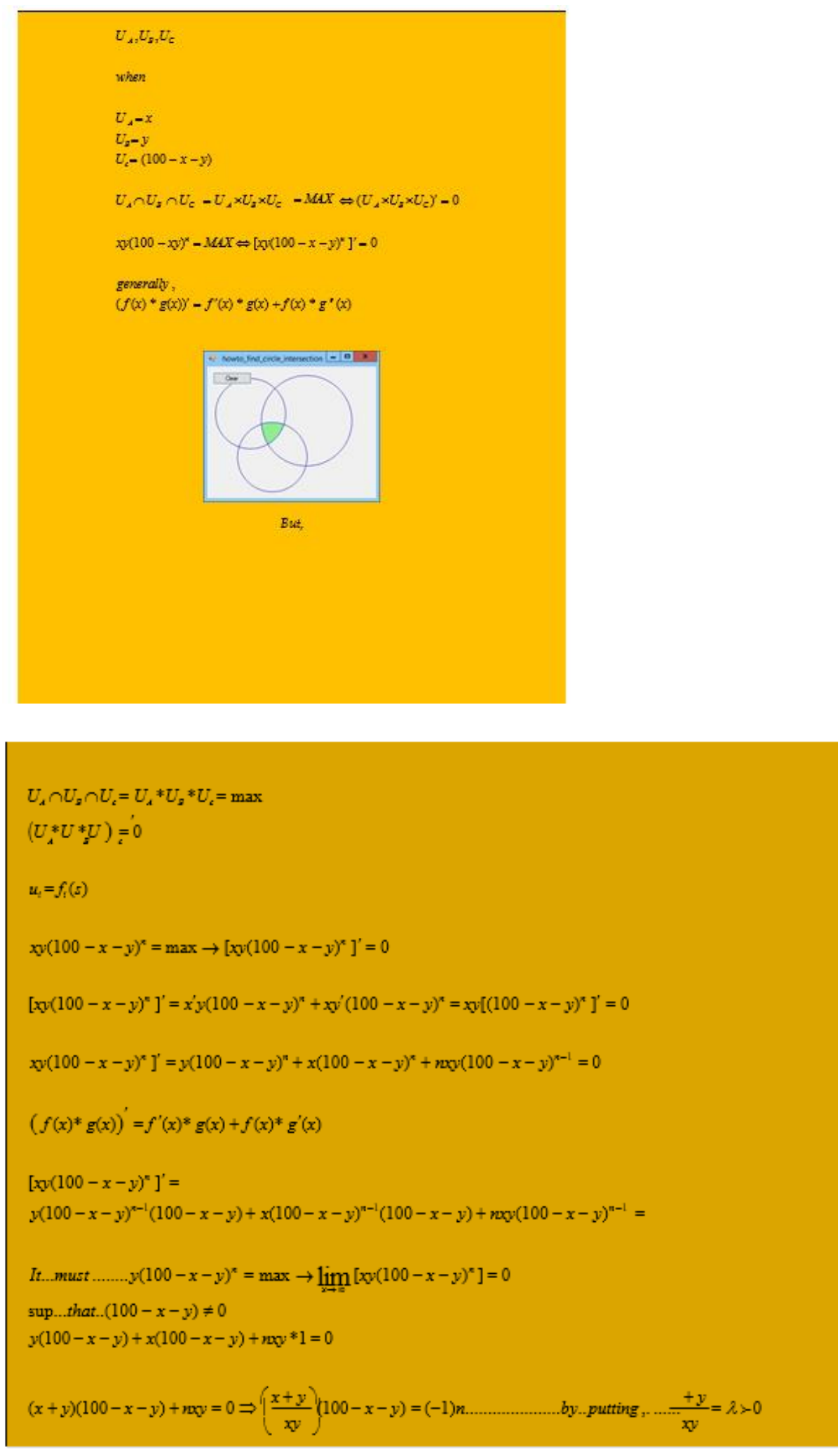
Prof. L. A. Papakonstantinidis

Professor Emeritus in Political Economy worked at the Local Government Dept (exPresident) of the School of Management and Economics (ex Director), Technological Educational Institute, University of PELOPONNESUS

$\lambda(100-x-y)=(-1) n \Rightarrow(100-x-y)=\frac{-n}{\lambda}=(-n) \frac{1}{\lambda}$

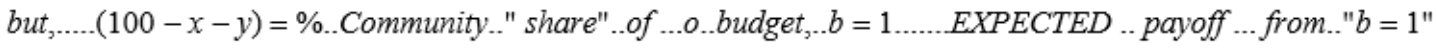

\%..Community...share $=(-n) \frac{1}{\lambda}(b)$........the... $(-n) \ldots$ denotes, , the..reduction

result... which..comes..from.the..Community..."reaction"...in..any. BARGAIN,...(by...its..3rd...role, .... i.e

as..an..Agent..of ..the..CITIZEN. -PRINCIPALrelation, ..Arbitrator , , , and..as...the..

Indepented ..3rd.barty)..to..the..total..budget.." $b^{\prime \prime . . . o f ~ . . t h e . ~ B A R G A I N ~}$

then, ...the... $i^{\text {th }} .$. player $;$ s.best..mixed ...strategy ( probability $=.$. a. .lottery ..over.

a.trinomial...distribution), is..the..best..strategies.. for. H. himself, as..well, as..the..best...strategies

..for..the..other...players, aswell..as..the..best.strategy..

for..the..Community..(the ..common....welfare)

Probability Rule

To take inter consideration, the uncertainty of the outcomes of Von Neumann and Morgenstern joint work (Neumann, John von and Morgenstern, Oskar 1946) addressed situations in which the outcomes of choices are not known with certainty, but have probabilities attached to them.

A notation for a lottery is as follows: if options A and B have probability $p$ and $1-p$ in the lottery, we write it as a linear combination:

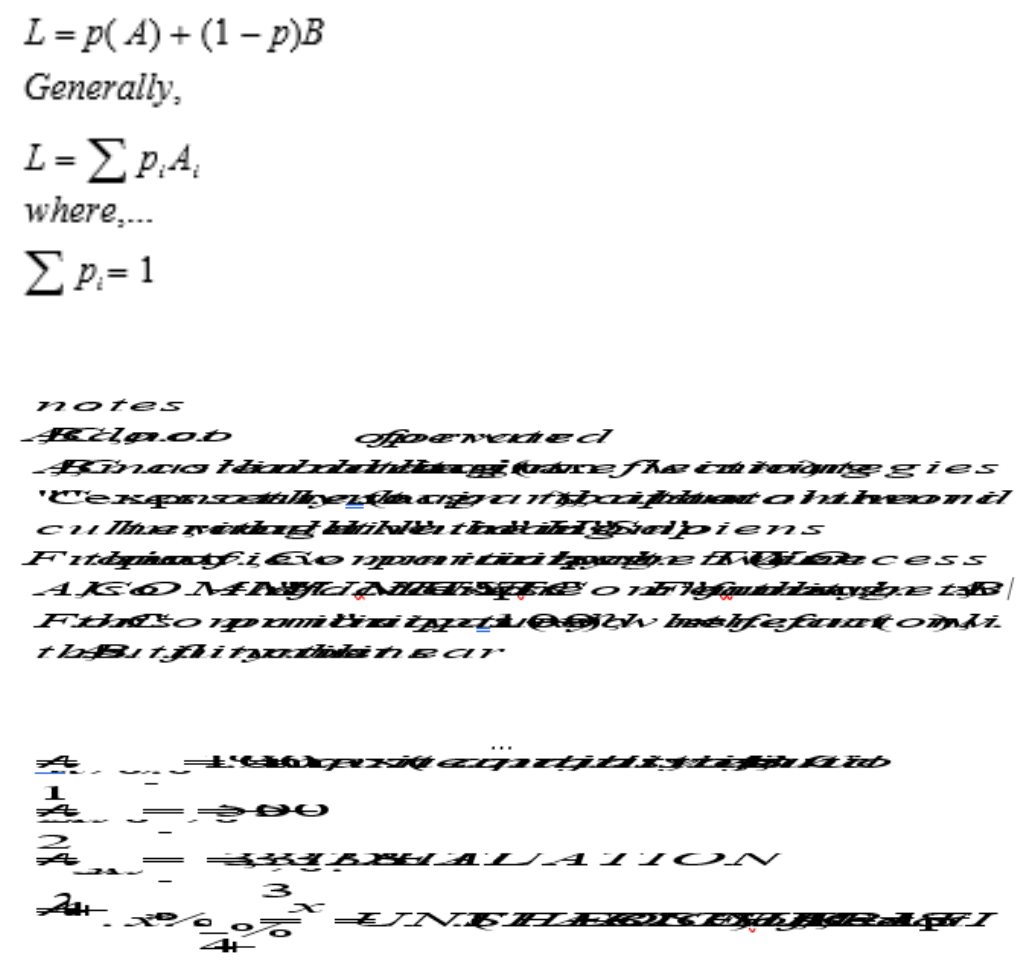

Case study

Intuitive Bargaining and Bounded Reality in the Jackpot of Life

Our brief synopsis about the dynamic bazars of human life is based upon the Nobel Prize in economics: 
Prof. L. A. Papakonstantinidis

Professor Emeritus in Political Economy worked at the Local Government Dept (exPresident) of the School of Management and Economics (ex Director), Technological Educational Institute, University of PELOPONNESUS

https://www.nobelprize.org/prizes/economic-sciences/1994/press-release/ and the connected research work of:

R.Selten \& G.Gigerenzer. 2002.

Bounded Rationality: The Adaptive Toolbox. MIT Press.

The combined work of all 4 authors (Nash, Harsanyi, Selten, Gigerenzer) has definitely demonstrated the physical and psychological constraints in (cooperative/non-cooperative) bargaining and negotiation processes, with reference to economic gaming behavior, decisionmaking and legal interaction of players. As a result, we can safely assume that the _information gap' is the dominant key factor for humans to =make a living'.

The sensitization process of the Papakonstantinidis model of the 3 win can achieve the full =angel's point', concerning a bottom-up collective bargaining process by propelling

meta-capitalist evolution forward, in terms of participatory capital formation. The intuitive 3 win approach calls for (capital- based) bargaining mutualism and has its analogy in the many living examples of biological mutualism. The model itself is an economic actualization of: https://plato.stanford.edu/entries/ethics-ancient/

The work of Balloni adds a very important socio-technical element to this economic systems improvement process, in terms of humanistic engineering and completes herewith the sensitization process for all participating players

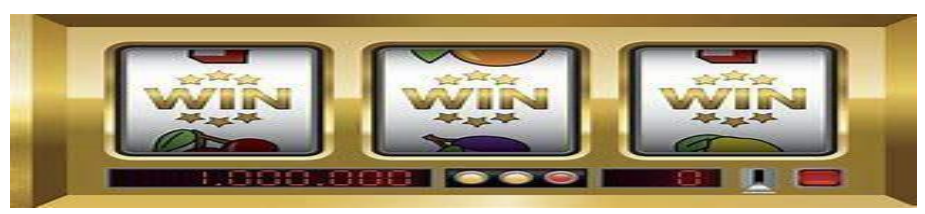

Stephen I. Ternyik lap 2020

\section{References}

- Nash, John (1950) "The Bargaining Problem" Econometrica 18

- Nash John (1951) "Non cooperative Game Theory (annals of Mathematics,1951 Vol. .........54, No. ..........2 (Sep., 1951)

- Neumann John von and Oscar Morgenstern (1944)" Theory of Games and Economic Behavior, published in 1944 by Princeton University Press, 2007 RETRIVE) "Theory of Games and Economic Behavior"60th Anniversary Commemorative Edition (2007) 60th Anniversary Commemorative Edition John von Neumann \& Oskar Morgenstern (With an introduction by Harold Kuhn and an afterword by Ariel Rubinstein

- Nasar, S.-Kuhun 1998. A Beautiful Mind. New York: Simon and Schuster.

- Nash, J.F., Jr. 1950. Equilibrium points in n-person games. Proceedings of the National ......Academy of Sciences, USA 36

- Nash, J.F., Jr. 1953. Two-person cooperative games Econometrica 21

- Nash, J.F., Jr. 1995. Autobiography Les Prix Nobel The Nobel Prizes 1994, ed. T. Frangsmyr Stockholm: Nobel Foundation. Online

- Neumann, J. von 1928. Zur theories der gesellschaftsspiele. Mathematische Annalen 100 English translation by S. Bergmann in Contributions to the Theory of 8 Nash, John Forbes (born 1928) Games IV, ed. R.D. Luce and A.W. Tucker Princeton: Princeton University Press, 1959.

- Papakonstantinidis LA (2013) The Intermediate Community: A Behavioral / Bargaining Approach For Conflict Resolution At The Local Level/ Bayesian Analysis EUROMED World Conference- Proceedings. P. 1443

- Papakonstantinidis LA (2012) The 'Win-Win-Win Papakonstantinidis Model' as a Bargaining Solution Analysis for Local Government Decision from Territory-Community to 'Behavioral' Community: The Case of Greece

- Papakonstantinidis LA (2016) Volume II titled "The "win-win-win papakonstantinidis model" VOLUME II: COLLECTION social choice, social welfare: theoretical background 2016 RESEARCH GATE-Papakonstantinidis LA (1997): the "S.H.I.E.L.D model" (the 
Prof. L. A. Papakonstantinidis

Professor Emeritus in Political Economy worked at the Local Government Dept (exPresident) of the School of Management and Economics (ex Director), Technological Educational Institute, University of PELOPONNESUS

Sensitive Harmonic Integrated Endogenous Local Development")- Presentation Book of Proceedings "World Conference "Tourismo Verde", Rome, 1997

- Papakonstantinidis L.A(2002-August 14) "The win-win-win model" Euracademy Guide The Visby University-Gotland-SW

- Papakonstantinidis, L. (2004). "Sensitization as a form of knowledge creation and the Win-Win-Win Model..." Scientific Review of Applied Research, Vol VIII, No 2 /2003, pp 89-108, ISSN 1106-4110

- Thomas Kronberger AND Leonidas A Papakonstantinidis (2019) "The Win-Win-Win Papakonstantinidis Model": Bargaining Possibilities When there are Three Involved Parties on a Labour Market and two of them are Active Decision- Makers. -Cases Greece-Germany" International Journal of Innovation and Economic Development ISSN 1849-7020 (Print) ISSN 1849-7551 (Online)

- Papakonstantinidis LA (2013) "Involving Communities In Rural Tourism: A "Win-WinWin Papakonstantinidis Model" Methodological Approach Case Studies: Women Rural Tourism Cooperatives: A) Gargaliani, Peloponnesus Area (South-West Gr) B) Wert (Women Entrepreneurs In Rural Tourism) EU Program : Win - Win -Win Papakonstantinidis Model" As A Recognized (In European- Wert Net- Level) Rural Tourism Methodological Tool" Book Proceedings Pp 80-109 Reports 108 Communities As A Part Of Sustainable Rural Tourism - Success Factor Or Inevitable Burden? Proceedings Of The Community Tourism Conference, 10th - 11th September 2013 Kotka, Finland Merja Lohdesmסki Ja

- Wilkinson, K. (1991). The Community in Rural America Greenwood Press:NYC

- Theocharis, R. (1959). "On the stability of the Cournot solution on the oligopoly problem" Review of economic Studies 1959;27

- Thirion, S. (2000). "Flag Theme and Local Development", LEADER Magazine, European Observatory for the Leader EU initiative- 2000, Fall, Bruxelles iss 8 Aug 2000

- Ulen, T. (1999). "Rational Choice Theory in Law and Economics" Northwestern University Law Review vol 95 issue 4 Northwestern University School of Law Printed in U.S.A

- Varoufakis, Y. (2006)"Game Theory": (trnsl) Edition: DARDANOS-GUNDEBERG 